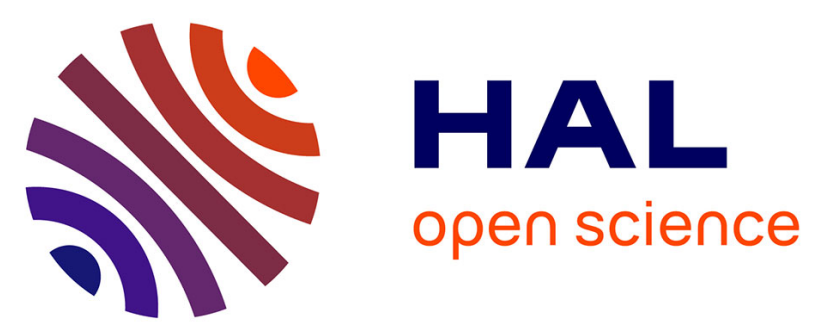

\title{
Calculation of IR frequencies and intensities in electrical and mechanical anharmonicity approximations: Application to small water clusters
}

\author{
Didier Bégué, Isabelle Baraille, P. A Garrain, A. Dargelos, T. Tassaing
}

\section{- To cite this version:}

Didier Bégué, Isabelle Baraille, P. A Garrain, A. Dargelos, T. Tassaing. Calculation of IR frequencies and intensities in electrical and mechanical anharmonicity approximations: Application to small water clusters. Journal of Chemical Physics, 2010, 133 (3), pp.034102. 10.1063/1.3457482 . hal-03227496

\section{HAL Id: hal-03227496 \\ https://hal-univ-pau.archives-ouvertes.fr/hal-03227496}

Submitted on 17 May 2021

HAL is a multi-disciplinary open access archive for the deposit and dissemination of scientific research documents, whether they are published or not. The documents may come from teaching and research institutions in France or abroad, or from public or private research centers.
L'archive ouverte pluridisciplinaire HAL, est destinée au dépôt et à la diffusion de documents scientifiques de niveau recherche, publiés ou non, émanant des établissements d'enseignement et de recherche français ou étrangers, des laboratoires publics ou privés. 


\title{
Calculation of IR frequencies and intensities in electrical and mechanical anharmonicity approximations: Application to small water clusters
}

\author{
D. Bégué, ${ }^{1, a)}$ I. Baraille, ${ }^{1, a)}$ P. A. Garrain, ${ }^{1,2}$ A. Dargelos, ${ }^{1}$ and T. Tassaing $^{3}$ \\ ${ }^{1}$ Institut Pluridisciplinaire de Recherche sur l'Environnement et les Matériaux (IPREM), UMR 5254 CNRS- \\ Equipe de Chimie Physique, Université de Pau et des Pays de l'Adour, 2 Avenue du Président Angot, \\ 64053 Pau Cedex 9, France \\ ${ }^{2}$ Laboratoire de Physico-Chimie des Surfaces, Ecole Nationale Supérieur de Chimie de Paris, UMR 7045 \\ CNRS, 11 rue Pierre et Marie Curie, 75005 Paris, France \\ ${ }^{3}$ Institut des Sciences Moléculaires (ISM), UMR 5255 CNRS, Université Bordeaux I, 351 Cours de la \\ Libération, 33405 Talence Cedex, France
}

(Received 16 February 2010; accepted 7 June 2010; published online 15 July 2010)

\begin{abstract}
We present a method for automatic computation of infrared (IR) intensities using parallel variational multiple window configuration interaction wave functions ( $\mathrm{P}_{-} \mathrm{VMWCI}_{2}$ algorithm). Inclusion of both mechanical and electrical anharmonic effects permits fundamental vibrational frequencies, including combinations and overtones, to be assigned. We use these developments to interpret the near-IR (NIR) and mid-IR (MIR) spectra of individual water clusters $(\mathrm{H} 2 \mathrm{O})_{\mathrm{n}}(\mathrm{n}=1-4)$. Cyclic and linear systems are studied to provide equivalent reference theoretical data to investigate the structure of water as a function of density using NIR and MIR experimental spectra. Various density functional theory methods for generating the potential energy surface have been compared to reference results obtained at the $\operatorname{CCSD}(\mathrm{T})$ level [X. Huang et al., J. Chem. Phys. 128, 034312 (2008)]. For cyclic clusters, the IR intensities and frequencies obtained using B1LYP/cc-pVTZ are found to be in very good agreement with the available experimental values and of the same orders of magnitude as the reference theoretical values. These data are completed by the vibrational study of linear systems. () 2010 American Institute of Physics. [doi:10.1063/1.3457482]
\end{abstract}

\section{INTRODUCTION}

During the past decade, there has been an increasing interest in the study of the structure and dynamics of water at high temperatures and pressures, in particular in the supercritical domain. The usefulness of supercritical water is related to the drastic change in its thermochemical properties as a solvent from those at ambient conditions. ${ }^{1-3}$ It is now well established that hydrogen bonds persist above the critical temperature and that the individual molecules remain bonded in small molecular clusters. Quantitative studies of the size and the structure of such clusters are important in order to fully understand the properties of supercritical water. Numerous experimental and theoretical investigations have been devoted to the study of supercritical water structure and dynamics. ${ }^{4-9}$ Among the various approaches, near infrared (NIR) and mid-IR (MIR) vibrational spectroscopies are powerful methods to investigate the structure of water as a function of density due to the considerable sensitivity of $\mathrm{OH}$ stretching frequencies to hydrogen bonding. ${ }^{6,10}$ Spectra resulting from these vibrational regions are believed to reflect not only the local structures of the clusters but also their relative concentration. Therefore, the quantitative analysis of such spectral database on a decomposition into the spectral components corresponding to the various water clusters present will allow a determination of their relative concentration. It is important to note that only quantum-chemistry

\footnotetext{
${ }^{a)}$ Authors to whom correspondence should be addressed. Electronic addresses: didier.begue@univ.pau.fr and isabelle.baraille@univ-pau.fr.
}

calculations permit a simultaneous assignment of the various clusters while having accurate access to the vibrational spectra of the individual clusters. ${ }^{11}$ In the MIR and NIR regions, these calculations must include anharmonic corrections to simulate fundamental vibrational frequencies as well as combination and overtone frequencies. ${ }^{12}$ Moreover, the knowledge of the related intensities ${ }^{13,14}$ should constitute precious additional information: it allows to confirm some experimental attributions for nonfundamental bands and to interpret quantitatively the experimental data. However, the calculation of vibrational intensities ${ }^{15}$ for the overtones and combinations needs the breakdown of the double-harmonic approximation which implies the determination of both anharmonic potential energy surface (PES) and dipole moment function beyond the first order. As a consequence, few automated methods have been developed. One standard approach, which is based on the treatment of the anharmonicity correction as a perturbation of the harmonic Hamiltonian, permits a calculation of the IR intensities of only the fundamental frequencies. Other methods such as the parallel vibrational multiple window configuration interaction (P_VMWCI) (Ref. 16) or vibrational mean field configuration interaction ${ }^{16,17}$ or vibrational coupled cluster (VCC) theory ${ }^{18}$ variationally treat the vibrational Hamiltonian ${ }^{19}$ in a finite space of selected vibrational configurations. These methods have proven to be efficient for the prediction of vibrational frequencies of medium size molecules. Recently, the calculation of IR intensities from P_VMWCI vibrational wave functions has been implemented in the parallel computer 
code ${ }^{20}$ P_ANHARM_V2.0. ${ }^{21}$ Our objective is to use these developments to interpret the NIR and MIR spectra of water and in particular in the supercritical phase. In the first step, we managed to reproduce the vibrational properties of small water clusters to check the validity of our approach on these systems. In this first double-paper we focus on the most stable conformations of $\left(\mathrm{H}_{2} \mathrm{O}\right)_{n}$ on the two different typephase (supercritical and gas phases) clusters for $n=2-4$ where experimental data are available. In the vast majority of cases, only gas-phase clusters are studied. Beyond the dimer with a single hydrogen bond (see, for example, Ref. 22), these systems are cyclic with the basic structural unit being a single-proton donor and a single-proton acceptor water molecule (see, for example, Ref. 23). In a second paper, we will use these results to interpret qualitatively the evolution of both the MIR and NIR spectra of supercritical water as a function of the density. We will show that a full interpretation of these spectra requires the introduction of linear conformations.

This paper is organized as follows. In Sec. II, we detail the theory of IR intensity calculation in the context of the $\mathrm{P}_{-} \mathrm{VMWCI}_{2}$ method. In Sec. III, methodological considerations (such as basis sets and electronic structure methods) are discussed. This analysis, based on geometry optimizations and (an)harmonic frequencies, allows a determination of the more efficient computational conditions for the potential surface and with respect to the $\mathrm{P}_{-} \mathrm{VMWCI}_{2}$ method. In Sec. IV, we report the nomenclature used in this work. The main results are discussed in Sec. V.

\section{METHODOLOGY}

$A b$ initio determination of vibrational intensities requires calculating the transition matrix elements of the dipole moment between the initial and final vibrational states. A common starting point for most $a b$ initio methods is the standard separation of electronic and nuclear motions within the framework of the Born-Oppenheimer approximation. As a consequence, the total wave function is written as a product of nuclear and electronic functions, the nuclear motion being determined by the potential electronic energy. The nuclear part describes both the rotation and vibration of the molecular system. The calculated transition intensity between the initial $\Psi_{\mathrm{i}}^{\mathrm{v}}$ and final $\Psi_{\mathrm{f}}^{\mathrm{v}}$ vibrational states can then be expressed (in $\mathrm{km} \mathrm{mol}^{-1}$ ) as

$$
\mathrm{I}_{\mathrm{if}}=\frac{2 \pi^{2} \mathrm{~N}_{\mathrm{A}}}{3 \mathrm{hc} \varepsilon_{0}} \bar{\nu}_{\mathrm{if}}\left\langle\Psi_{\mathrm{i}}^{\mathrm{v}}|\mu(\mathrm{Q})| \Psi_{\mathrm{f}}^{\mathrm{v}}\right\rangle^{2}\left(\mathrm{~N}_{\mathrm{i}}-\mathrm{N}_{\mathrm{f}}\right),
$$

where $\mu(\mathrm{Q})=\left\langle\Psi_{\mathrm{g}}^{\mathrm{e}}|\mu| \Psi_{\mathrm{g}}^{\mathrm{e}}\right\rangle$ is the dipole moment as a function of the nuclear coordinates $\mathrm{Q}, \Psi_{\mathrm{g}}^{\mathrm{e}}$ being the electronic ground state. $\bar{\nu}_{\text {if }}$ is the frequency of the transition $\left(\right.$ in $\mathrm{cm}^{-1}$ ). The factor $\left(\mathrm{N}_{\mathrm{i}}-\mathrm{N}_{\mathrm{f}}\right)$ is the difference in the number of molecules between the initial and final states calculated assuming a Boltzmann distribution and thus depends on temperature. For the low-frequency modes, the temperature effect may be relatively important. We have inserted the usual physical constants in the first term (c is the speed of light; $\varepsilon_{0}$, the permittivity of vacuum; $h$, the Planck's constant; and $\mathrm{N}_{\mathrm{A}}$, the Avogadro's constant).
At the moment, the well-established post-Hartree-Fock (configuration interaction or coupled cluster) or density functional theory (DFT) methods enable accurate calculations of the electronic structure. The majority of the electronic structure packages perform routinely the calculations of the fundamental vibrational harmonic frequencies by diagonalizing the matrix of second derivatives of energy with respect to the nuclear coordinates. The related IR intensities are then calculated within the so-called double harmonic approximation in which the vibrational wave function is represented by a product of the harmonic-oscillator functions and the dipole moment function as a linear function of normal coordinates. The intensity of the sth fundamental mode described by the $\mathrm{Q}_{\mathrm{s}}$ normal coordinate is given by

$$
\mathrm{I}_{\mathrm{s}}=\frac{\mathrm{N}_{\mathrm{A}}}{12 \mathrm{c}^{2} \varepsilon_{0}}\left(\frac{\partial \mu}{\partial \mathrm{Q}_{\mathrm{s}}}\right)_{0}^{2}=974.892 \mu_{\mathrm{s}}^{2},
$$

where $\mu_{\mathrm{s}}=\left(\partial \mu / \partial \mathrm{Q}_{\mathrm{s}}\right)_{0}$ (where the index 0 indicates the equilibrium geometry) is expressed in $\mathrm{e} \mathrm{u}^{-1 / 2}$ (with " $\mathrm{u}$ " the unified atomic mass unit and "e" the elementary charge) and $\mathrm{I}_{\mathrm{s}}$ in $\mathrm{km} \mathrm{mol}^{-1}$.

However, the presence of overtones and combinations in the IR spectra is a manifestation of the breakdown of the double-harmonic approximation. The treatment of transition energies and probabilities requires consideration of both mechanical anharmonicity (anharmonicity of the potential) and nonlinear dependence of the dipole moment on the normal coordinates (electrical anharmonicity), since both effects are expected to increase the accuracy of the vibrational calculations.

The approach developed here to compute the vibrational spectrum consists of four steps: (i) geometry optimization; (ii) calculation of harmonic, cubic, and quartic force constants in the basis of curvilinear coordinates at the optimum geometry; (iii) calculation of the harmonic vibrational modes by employing the Wilson method to obtain the vibrational equation in terms of reduced normal coordinates $\mathrm{Q}_{s}$; and (iv) application of the variational treatment to solve the vibrational equation.

The harmonic, cubic, and quartic force fields were set up from a least-squares fit performed to energies on a grid of points described in terms of curvilinear coordinates (bond and angle displacements). Corresponding to the standard rovibrational separation of the nuclear motions within the framework of the Eckart's conditions, the quantum vibrational part of the nuclear Hamiltonian is written in the basis of curvilinear coordinates $s_{k}$ and their conjugate moments $\mathrm{p}_{\mathrm{s}_{\mathrm{k}}}$

$$
\mathrm{H}=\frac{1}{2} \sum_{\mathrm{i}, \mathrm{j}} \mathrm{g}_{\mathrm{ij}}(\mathrm{s}) \mathrm{p}_{\mathrm{s}_{\mathrm{i}}} \mathrm{p}_{\mathrm{s}_{\mathrm{j}}}+\mathrm{V}(\mathrm{s}),
$$

where $g_{i j}$ is the element of the G matrix described by Wilson

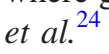

As is usually done for the potential function $\mathrm{V}(\mathrm{s})$, the kinetic part of the Hamiltonian can be written as a Taylor expansion in terms of the curvilinear displacement coordinates set, 


$$
\begin{aligned}
\mathrm{T}= & \frac{1}{2} \sum_{\mathrm{i}, \mathrm{j}} \mathrm{g}_{\mathrm{ij}}(0) \mathrm{p}_{\mathrm{s}_{\mathrm{i}}} \mathrm{p}_{\mathrm{s}_{\mathrm{j}}}+\frac{1}{2} \sum_{\mathrm{i}, \mathrm{j}, \mathrm{k}} \mathrm{g}_{\mathrm{ijk}} \mathrm{p}_{\mathrm{s}_{\mathrm{i}}} \mathrm{s}_{\mathrm{k}} \mathrm{p}_{\mathrm{s}_{\mathrm{j}}} \\
& +\frac{1}{2} \sum_{\mathrm{i}, \mathrm{j}, \mathrm{k}} \mathrm{g}_{\mathrm{iijk}} \mathrm{p}_{\mathrm{s}_{\mathrm{i}}} \mathrm{s}_{\mathrm{j}} \mathrm{s}_{\mathrm{k}} \mathrm{p}_{\mathrm{s}_{\mathrm{i}}}
\end{aligned}
$$

with

$$
\begin{aligned}
& g_{i j}(s)=g_{i j}(0)+\sum_{k} g_{i j k} s_{k}+\frac{1}{2} \sum_{k, l} g_{i j k l} s_{k} s_{1}+\cdots \\
& g_{i j k}=\left(\frac{\partial g_{i j}}{\partial s_{k}}\right)_{0} \text { and } g_{i j k l}=\left(\frac{\partial^{2} g_{i j}}{\partial s_{k} \partial s_{1}}\right)_{0} .
\end{aligned}
$$

The anharmonic part of the potential includes all the three and four-body terms. In our calculations, both the kinetic and the potential parts of the vibrational Hamiltonian are expressed in the basis of reduced normal coordinates $Q_{s}$ and conjugated momenta operators $\mathrm{P}_{\mathrm{s}}$.

The dimensionless normal modes are obtained by solving the classical Wilson equation,

$$
\mathrm{FGL}=\mathrm{L} \Lambda .
$$

The diagonal terms of the $\Lambda$ matrix are the squares of the harmonic frequencies $\omega_{\mathrm{s}}$. The dimensionless normal coordinates $\mathrm{Q}$ are deduced from the curvilinear coordinates s by the transformation,

$$
\mathrm{Q}=\left(\Lambda^{+1 / 4} \mathrm{~L}^{-1}\right) \mathrm{S} .
$$

The anharmonic vibrational wave functions $\Psi_{\mathrm{i}}^{\mathrm{v}}$ and $\Psi_{\mathrm{f}}^{\mathrm{v}}$ are expanded as linear combinations of products of harmonic oscillators, each containing a single normal coordinate $\mathrm{Q}_{\mathrm{s}}$ and defined by a single quantum number $\mathrm{v}_{\mathrm{s}}$,

$$
\begin{aligned}
& \Psi_{\mathrm{i}}^{\mathrm{f}}=\sum_{\mathrm{n}} \mathrm{C}_{\mathrm{in}}\left|\sum_{\mathrm{s}} \mathrm{v}_{\mathrm{sn}} \omega_{\mathrm{s}}\right\rangle, \\
& \Psi_{\mathrm{f}}^{\mathrm{v}}=\sum_{\mathrm{m}} \mathrm{C}_{\mathrm{fm}}\left|\sum_{\mathrm{r}} \mathrm{v}_{\mathrm{rm}} \omega_{\mathrm{r}}\right\rangle,
\end{aligned}
$$

where the harmonic configurations are indicated by the harmonic frequency (frequencies) $\omega_{\mathrm{s}}$ with nonvanishing quantum number(s) in the product. For example, $\left|\omega_{\mathrm{s}}+\omega_{\mathrm{r}}\right\rangle$ is the configuration in which all quantum numbers are equal to zero, except $\mathrm{v}_{\mathrm{s}}=1$ and $\mathrm{v}_{\mathrm{r}}=1$.

The P_VMWCI algorithm is used to solve the vibrational equation. This method generates several vibrational configuration spaces starting from different spectral "windows." For each window, the related Hamiltonian representation is built while accounting for symmetry considerations. The matrix diagonalization is based on the Bloch-Davidson algorithm. An iterative process builds each variational subspace including all of the harmonic configurations, each of which corresponds to the specific spectral window. Several studies on medium size molecules showed the performance of this method for the calculation of the vibrational frequencies.

On the other hand the dipole moment $\mu$ can be expanded as a power series of the normal coordinates $\mathrm{Q}_{\mathrm{s}}$,

$$
\mu=\mu_{0}+\sum_{\mathrm{s}} \mu_{\mathrm{s}} \mathrm{Q}_{\mathrm{s}}+\frac{1}{2 !} \sum_{\mathrm{s}, \mathrm{r}} \mu_{\mathrm{sr}} \mathrm{Q}_{\mathrm{s}} \mathrm{Q}_{\mathrm{r}}+\cdots,
$$

where $\mu_{\mathrm{s}}=\left(\partial \mu / \partial \mathrm{Q}_{\mathrm{s}}\right)_{0}$ and $\mu_{\mathrm{sr}}=\left(\partial^{2} \mu / \partial \mathrm{Q}_{\mathrm{s}} \partial \mathrm{Q}_{\mathrm{r}}\right)_{0}$. Here the couplings between three and more normal modes are neglected. Other works in both normal and local mode approximations were previously developped. ${ }^{15,25}$ All the approximations were shown to work reasonably for both isolated and weakly bound van der Waals complexes containing water. Evaluation of the Cartesian components of the dipole moment derivatives with respect to the normal coordinates requires definition of (3N-6) vibrational coordinates, which may be orthogonal to the six pure rotational and translational coordinates. So the Eckart conditions are satisfied and the rototranslational and vibrational kinetic contributions vanish.

The development of the dipole moment in Eq. (5) leads to the following expression of the transition moments:

$$
\begin{aligned}
\left\langle\Psi_{\mathrm{i}}^{\mathrm{v}}|\mu| \Psi_{\mathrm{f}}^{\mathrm{v}}\right\rangle= & \sum_{\mathrm{s}}\left[\mu_{\mathrm{s}}\left\langle\Psi_{\mathrm{i}}^{\mathrm{v}}\left|\mathrm{Q}_{\mathrm{s}}\right| \Psi_{\mathrm{f}}^{\mathrm{v}}\right\rangle+\frac{1}{2} \mu_{\mathrm{ss}}\left\langle\Psi_{\mathrm{i}}^{\mathrm{v}}\left|\mathrm{Q}_{\mathrm{s}}^{2}\right| \Psi_{\mathrm{f}}^{\mathrm{v}}\right\rangle\right. \\
& \left.+\sum_{\mathrm{r}>\mathrm{s}} \mu_{\mathrm{sr}}\left\langle\Psi_{\mathrm{i}}^{\mathrm{v}}\left|\mathrm{Q}_{\mathrm{s}} \mathrm{Q}_{\mathrm{r}}\right| \Psi_{\mathrm{f}}^{\mathrm{v}}\right\rangle\right]
\end{aligned}
$$

The first term $I_{i f}^{(1)}=\Sigma_{s} \mu_{s}\left\langle\Psi_{i}^{v}\left|Q_{s}\right| \Psi_{f}^{v}\right\rangle$ mainly traduces the effect of the mechanical anharmonicity on the transition moment, i.e., the intensity redistribution from the fundamental modes to the overtones or combination transitions via the development of the final state on the monoexcited configurations $\left|\omega_{\mathrm{s}}\right\rangle$. The only nonvanishing terms in $\mathrm{I}_{\text {if }}^{(1)}$ imply two harmonic configurations differing only by one vibration quantum number (i.e., $\Delta \mathrm{v}_{\mathrm{s}}=\mathrm{v}_{\mathrm{sn}}-\mathrm{v}_{\mathrm{sm}}=1$ and for $\mathrm{t} \neq \mathrm{s}, \Delta \mathrm{v}_{\mathrm{t}}$ $=0$, i.e., $\left.\mathrm{v}_{\mathrm{tn}}=\mathrm{v}_{\mathrm{tm}}\right)$,

$$
\begin{aligned}
& \left\langle\mathrm{v}_{\mathrm{sn}} \omega_{\mathrm{s}}+\sum_{\mathrm{t} \neq \mathrm{s}} \mathrm{v}_{\mathrm{tn}} \omega_{\mathrm{t}}\left|\mathrm{Q}_{\mathrm{s}}\right|\left(\mathrm{v}_{\mathrm{sn}}+1\right) \omega_{\mathrm{s}}+\sum_{\mathrm{t} \neq \mathrm{s}} \mathrm{v}_{\mathrm{tn}} \omega_{\mathrm{t}}\right\rangle \\
& =\left(\frac{\mathrm{v}_{\mathrm{s}_{\mathrm{n}}}+1}{2 \gamma_{\mathrm{s}}}\right)^{1 / 2},
\end{aligned}
$$

where $\gamma_{\mathrm{s}}=4 \pi^{2} \mathrm{c} \omega_{\mathrm{s}} / \mathrm{h}$ with $\omega_{\mathrm{s}}$ in $\mathrm{cm}^{-1}$.

The terms developed on the second derivatives of the molecular dipole moment with respect to the normal coordinates include the effect of electrical anharmonicity which contributes to the intensities of binary overtones $\left|2 \nu_{\mathrm{s}}\right\rangle$ or combinations $\left|\nu_{\mathrm{s}}+\nu_{\mathrm{r}}\right\rangle$ via $\mu_{\mathrm{ss}}\left\langle 0\left|\mathrm{Q}_{\mathrm{s}}^{2}\right| 2 \nu_{\mathrm{s}}\right\rangle$ and $\mu_{\mathrm{sr}}\left\langle 0\left|\mathrm{Q}_{\mathrm{s}} \mathrm{Q}_{\mathrm{r}}\right| \nu_{\mathrm{s}}\right.$ $\left.+\nu_{\mathrm{r}}\right\rangle$, respectively. Both mechanical anharmonicity and nonlinear dependence of the dipole moment are expected to contribute to the intensities of nonfundamental bands in the same order. The transition moments $\left\langle\Psi_{\mathrm{i}}^{\mathrm{v}}\left|\mathrm{Q}_{\mathrm{s}}^{2}\right| \Psi_{\mathrm{f}}^{\mathrm{v}}\right\rangle$ are developed on the nonvanishing integrals,

$$
\begin{gathered}
\left\langle\mathrm{v}_{\mathrm{sn}} \omega_{\mathrm{s}}+\sum_{\mathrm{t} \neq \mathrm{s}} \mathrm{v}_{\mathrm{tn}} \omega_{\mathrm{t}}\left|\mathrm{Q}_{\mathrm{s}}^{2}\right|\left(\mathrm{v}_{\mathrm{sn}}+2\right) \omega_{\mathrm{s}}+\sum_{\mathrm{t} \neq \mathrm{s}} \mathrm{v}_{\mathrm{tn}} \omega_{\mathrm{t}}\right\rangle \\
=\frac{\left[\left(\mathrm{v}_{\mathrm{s}_{\mathrm{n}}}+1\right)\left(\mathrm{v}_{\mathrm{s}_{\mathrm{n}}}+2\right)\right]^{1 / 2}}{2 \gamma_{\mathrm{s}}},
\end{gathered}
$$




$$
\left\langle\mathrm{v}_{\mathrm{sn}} \omega_{\mathrm{s}}+\sum_{\mathrm{t} \neq \mathrm{s}} \mathrm{v}_{\mathrm{tn}} \omega_{\mathrm{t}}\left|\mathrm{Q}_{\mathrm{s}}^{2}\right| \mathrm{v}_{\mathrm{sn}} \omega_{\mathrm{s}}+\sum_{\mathrm{t} \neq \mathrm{s}} \mathrm{v}_{\mathrm{tn}} \omega_{\mathrm{t}}\right\rangle=\frac{1}{\gamma_{\mathrm{s}}}\left(\mathrm{v}_{\mathrm{s}_{\mathrm{n}}}+\frac{1}{2}\right),
$$

where the two harmonic configurations are either the same [Eq. (9)] or differ by one vibration quantum number [Eq. (8)] (i.e., $\Delta \mathrm{v}_{\mathrm{s}}=\mathrm{v}_{\mathrm{sn}}-\mathrm{v}_{\mathrm{sm}}=2$ and for $\mathrm{s} \neq \mathrm{t}, \Delta \mathrm{v}_{\mathrm{t}}=0$, i.e., $\mathrm{v}_{\mathrm{tn}}=\mathrm{v}_{\mathrm{tm}}$ ).

Moreover, $\left\langle\Psi_{\mathrm{i}}^{\mathrm{v}}\left|\mathrm{Q}_{\mathrm{s}} \mathrm{Q}_{\mathrm{r}}\right| \Psi_{\mathrm{f}}^{\mathrm{v}}\right\rangle$ requires the calculations of terms such as

$$
\begin{gathered}
\left\langle\mathrm{v}_{\mathrm{sn}} \omega_{\mathrm{s}}+\mathrm{v}_{\mathrm{rn}} \omega_{\mathrm{r}}+\sum_{\substack{\mathrm{t} \neq \mathrm{s} \\
\mathrm{t} \neq \mathrm{r}}} \mathrm{v}_{\mathrm{tn}} \omega_{\mathrm{t}}\left|\mathrm{Q}_{\mathrm{s}} \mathrm{Q}_{\mathrm{r}}\right|\left(\mathrm{v}_{\mathrm{sn}}+1\right) \omega_{\mathrm{s}}+\left(\mathrm{v}_{\mathrm{rn}}+1\right) \omega_{\mathrm{r}}\right. \\
\left.+\sum_{\substack{\mathrm{t} \neq \mathrm{s} \\
\mathrm{t} \neq \mathrm{r}}} \mathrm{v}_{\mathrm{tn}} \omega_{\mathrm{t}}\right\rangle=\left(\frac{\mathrm{v}_{\mathrm{s}_{\mathrm{n}}}+1}{2 \gamma_{\mathrm{s}}}\right)^{1 / 2}\left(\frac{\mathrm{v}_{\mathrm{r}_{\mathrm{n}}}+1}{2 \gamma_{\mathrm{r}}}\right)^{1 / 2}
\end{gathered}
$$

where the two harmonic configurations differ only by two vibration quantum numbers (i.e., $\Delta \mathrm{v}_{\mathrm{s}}=\mathrm{v}_{\mathrm{sn}}-\mathrm{v}_{\mathrm{sm}}=1, \Delta \mathrm{v}_{\mathrm{r}}=\mathrm{v}_{\mathrm{rn}}$ $-\mathrm{v}_{\mathrm{rm}}=1$, and for $\mathrm{t} \neq \mathrm{s} \neq \mathrm{r}, \Delta \mathrm{v}_{\mathrm{t}}=0$, i.e., $\left.\mathrm{v}_{\mathrm{tn}}=\mathrm{v}_{\mathrm{tm}}\right)$.

\section{COMPUTATIONAL DETAILS}

It is nowadays accepted that theoretical calculations can complement the knowledge of experimentalists. Theoretical chemists have proven to provide highly accurate results for small molecules, demonstrating the potential of calculations as key tools for the prediction and understanding of, for example, spectroscopic properties of medium size molecules.

Since the development of the classical double harmonic approximation, much progresses have been made very recently for the category of methods that add anharmonic corrections to the conventional normal mode methods. Several reasons may be given to explain such a situation on medium size molecules with numerous Fermi and Coriolis resonances. As stated above, handling all these interactions is virtually impossible with the only feasible method available at present, i.e., the perturbational approach, as was developed 10 years ago. Moreover, the required development of data processing for the description of these interactions by variational methods was only achieved in the mid-1990s. Nowadays, owing to efficient methods based on both perturbational and variational optimized concepts [namely, for example, perturbational theory (PT2), ${ }^{26-29}$ canonical Van Vleck perturbational theory, ${ }^{30,31}$ vibrational self-consistent field (VSCF), ${ }^{16,32-34}$ correlation-corrected vibrational selfconsistent field (cc-VSCF), ${ }^{35}$ partially separable vibrational self-consistent field, ${ }^{36}$ pseudospectral calculations, ${ }^{37}$ variational configuration interaction (VCI) theory, ${ }^{38-41}$ variationperturbation theory, ${ }^{42-45}$ vibrational coupled cluster (VCC), ${ }^{46,47}$ and parallel direct variation (PDV) (Ref. 20)], the average accuracy of current calculations on these small organic systems is between 1 and $5 \mathrm{~cm}^{-1}$ for stretching and bending bands and around $10-20 \mathrm{~cm}^{-1}$ for motions of larger amplitudes involving light atoms. This accuracy primarily depends on both the quality and the analytical form chosen for developing force fields. The limitations related to resolution of the vibrational Schrödinger equation are mainly technologic. For medium size-systems like small water clus- ters, these limitations are now being overcome by developments including highly parallelized software. We can therefore conclude that these approaches are exact for systems not exceeding 15 atoms and for a given force field.

However, these progresses on the wavenumber determination are not enough for fine vibrational assignments. Information on activities are needed but are rare for the methods listed just above. Among the pioneer developments in this area, let us cite methods that are based on a reduced Hamiltonian local mode approach (HCAO) in which the modes are inherently anharmonic. Complete references are available in Ref. 48 where differences between the two local and nonlocal, more or less automatic methods and accuracies, are presented. Kjaergaard's works are referenced in this field specially for the water cluster's studies. ${ }^{14,25,48-50}$

Anyway, for both approaches and for the frequency and intensity determinations, the main difficulty lies in the choice of the potential function model and in the accuracy of the calculated force constants. Today, these aspects are crucial for the study of the smallest systems because they directly affect the quality of the interpretation of experimental data. Let us cite again some computational references where theoreticians are now able to assess enough accurate models (see, for example, Refs. 51-58) in order to assign spectra and very accurately produce parameters pertaining to the far infrared characteristics. However, an attentive reading of these works shows how the PES determinations are not routine for the water clusters. The procedure finally adopted in this study is presented just below.

All harmonic calculations were performed with the MOLPRO (Ref. 59) and the GAUSSIAN 09 (Ref. 60) packages using various functionals, i.e., PBE, B1LYP, B3LYP methods (see Ref. 61 for complements). It is important to note here that the recently full-dimensional global CCSD(T)/aug-cc-pVTZ PES reported by Bowman and co-workers ${ }^{62,63}$ serves as a reference for our calculations on the stablest cyclic clusters in the gas phase. Additional ab initio calculations were also performed at both the MP2 and $\operatorname{CCSD}(\mathrm{T})$ levels of theory. As these last approaches are very time consuming, additional calculations based on the additivity of DFT anharmonic corrections to $\operatorname{CCSD}(\mathrm{T})$ harmonic force field were performed in this study to reduce the computational cost. ${ }^{64,65}$ They were carried out with the use of the FORCE software ${ }^{66}$ in order to determine hybrid CC//DFT PES as developed elsewhere. ${ }^{67}$ Finally, $a b$ initio calculations needed for the PES determinations were carried out by using (i) the recommended double zeta basis set of Pople ${ }^{68} 6-31+\mathrm{G}^{* *}$ (ii) or Dunning correlation consistent $\mathrm{pVTZ}(\mathrm{X}=\mathrm{D}, \mathrm{T}$, or $\mathrm{Q})$ Cartesian basis set family. ${ }^{69}$ Additional diffuse functions (aug-) were added in order to better describe the electronic delocalization of each cluster. Counterpoise (CP) estimates of the basis set superposition error (BSSE) in the evaluation of stabilization energies have been calculated for basis sets ranging from minimal to split-valence plus polarization quality. A complete description of the CP correction adapted to the methodologies used in the present work is well detailed in Ref. 70.

All anharmonic frequencies were calculated taking into account the most relevant vibrational interactions. First, as mentioned by Wang et al., ${ }^{63}\left(\mathrm{H}_{2} \mathrm{O}\right)_{n}$ clusters are very floppy 
complexes. The poor rectilinear description of the lowest frequency librations obtained with the use of quadratic standard PES artificially increases the coupling between those modes and the high frequency intramolecular ones studied. So, these libration modes were systematically disconnected from the monomers' vibrational ones in our PES fits. Second, in order to test the suitability of the polynomial PES form, exact vibrational levels were also benchmarked by a discrete variable representation (DVR) calculation by using ab initio calculations at all DVR points on $\mathrm{H}_{2} \mathrm{O}$ system. ${ }^{7-73}$ Third, anharmonic frequencies were calculated from the quartic force fields including fifth and sixth diagonal orders obtained for all systems using the variational vibrational treatment developed in the first version of the P_ANHAR software. This approach consists of taking an inventory of the vibrational configurations potentially needed for the description of the problem on the basis of the potential term values, taking into account the symmetry of each state and cutting the process into several spectral windows which are dealt within independent processes. The major advantage of this algorithm lies in its ability to provide, in several spectral ranges, smaller matrices that contain all the information needed, which makes the execution faster while being perfectly adapted to parallel calculations. For each symmetry, submatrices including 20000-30000 configurations are diagonalized in order to obtain about 50 converged eigenvalues with an accuracy of $1 \mathrm{~cm}^{-1}$. For details on the method, see Ref. 16. Based on the same procedure and in agreement with the methodology presented in the previous paragraph (i.e., calculations where the contribution of the second order derivatives of dipole moment in terms of normal coordinates is less important than those of the mechanical anharmonicity), IR intensities were also computed in the 1500-1700, 3000 $3600,5000-5900$, and $6300-7500 \mathrm{~cm}^{-1}$ regions in order to complement the vibrational analysis. The variational treatment, namely, $\mathrm{P}_{-} \mathrm{VMWCI}_{2}$ (parallel_variational multiple windows configuration of interaction-intensities), is now implemented in the last version of the P_ANHAR_V2.0 software ${ }^{20}$ Finally, together with the anharmonic part of the force field, the second order Coriolis couplings were also taken into account.

When all these conditions are combined, overtones, combinations, and fundamental bands are generally computed with an overall root-mean-square deviation of $1 \%$ with respect to the experimental values leading to a good confidence in our theoretical analysis.

\section{NOMENCLATURE}

The vibrational terminology employed in this work is what has been commonly adopted in the previous studies of cyclic water clusters ${ }^{63}$, i.e., "u" for "up," "d" for "down," "p" for "plane," b for "bisector." Molecules with the hydrogen atoms involved in hydrogen bonding are referred to as "donors," or otherwise, "acceptors," if their hydrogen atoms are not involved in this type of interaction. Furthermore, the hydrogen atoms involved in hydrogen bonding are tagged as "linked" ("L"), and otherwise, "free" or "libre" ("l"). Regarding the cyclic aggregates, the position of each hydrogen atom is defined relative to the plane of the hydrogen bonds (as all of the hydrogen bonds, between each pair of monomers, together form more or less a two-dimensional cycle in a cyclic aggregate). For example, the position "u" indicates the hydrogen atom to be "up" above the plane (see Fig. 1).

\section{RESULTS AND DISCUSSION}

\section{A. Structures}

We report about the most probable structures present in water under different thermodynamic states (supercritical fluid and gas), i.e., small water clusters of ring- and linearlike structure. Two experimental and theoretical considerations are the cause of the systems we have studied. (i) With the use of a hybrid hydrogen-bonding criterion applied to the analysis of Monte Carlo computer simulation approach, Kalinichev and Churakov ${ }^{74,75}$ found that up to $10 \%$ of water molecules constitute $\mathrm{H}$-bonded clusters even in low density supercritical water and the maximum size of such molecular complexes formed may contain as many as seven molecules per cluster under these conditions. By studying the relative abundance, geometric and energetic characteristics of all the topological conformations for each possible clusters, Kalinichev et al. showed that the open chainlike clusters are preferentially formed in supercritical water, while cyclic ringlike structures occur only rarely. (ii) In contrast, in gas phase under normal temperature and pressure conditions, it is now well established that the most stable structures for aggregates are of cyclic form ${ }^{76-80}$ (see Fig. 1).

Listed in Table I are the published results from the literature concerning the absolute minimum of each cyclic aggregate $(n=2-4)$. We invite the reader to consult publications by Leforestier et al.,${ }^{52,55}$ Xantheas et al. ${ }^{53,56}$ Taketsugu and Wales, ${ }^{51}$ Bukowski et al. ${ }^{54}$ and Bowman et al. ${ }^{62,63}$ for all energy and structural data at global minima. Also listed in Table I are the main results we have produced on linear structures of water clusters. As shown in this table, our B1LYP/cc-pVTZ calculations are in good agreement with experimental results as well as the values computed by Bowman et al. at the CCSD(T)/aug-cc-pVTZ level of theory [noted $\operatorname{CCSD}(\mathrm{T}) / \mathrm{avtz}]$ for cyclic clusters. The contribution to energy due to each hydrogen bond varies from -3.77 to $-6.14 \mathrm{kcal} / \mathrm{mol}$ for these aggregates considered in this work. The predicted contribution of energy at $-6.14 \mathrm{kcal} / \mathrm{mol}$ per hydrogen bond as proposed for large aggregates, i.e., tetramer, in our calculations, compares favorably with the experimental value of $-6,7 \mathrm{kcal} / \mathrm{mol}$ in ice. Note that the obtained values are highly dependent on the BSSE correction, and a calculation without including this correction would strongly overestimated the energy of H-bond. ${ }^{70,87}$ All the structural parameters we obtained for the most stable forms are naturally in agreement with Clementi's work ${ }^{82}$ which today seems to be the most complete in modeling water clusters with DFT methods. For the linear systems, however, we have not found any either computational or experimental references, other than those by Kalinichev. ${ }^{74,75}$ 


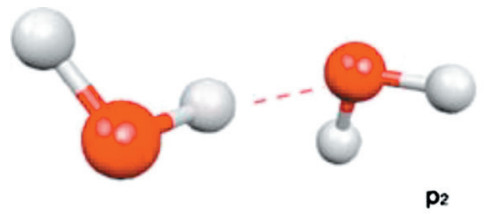

p1
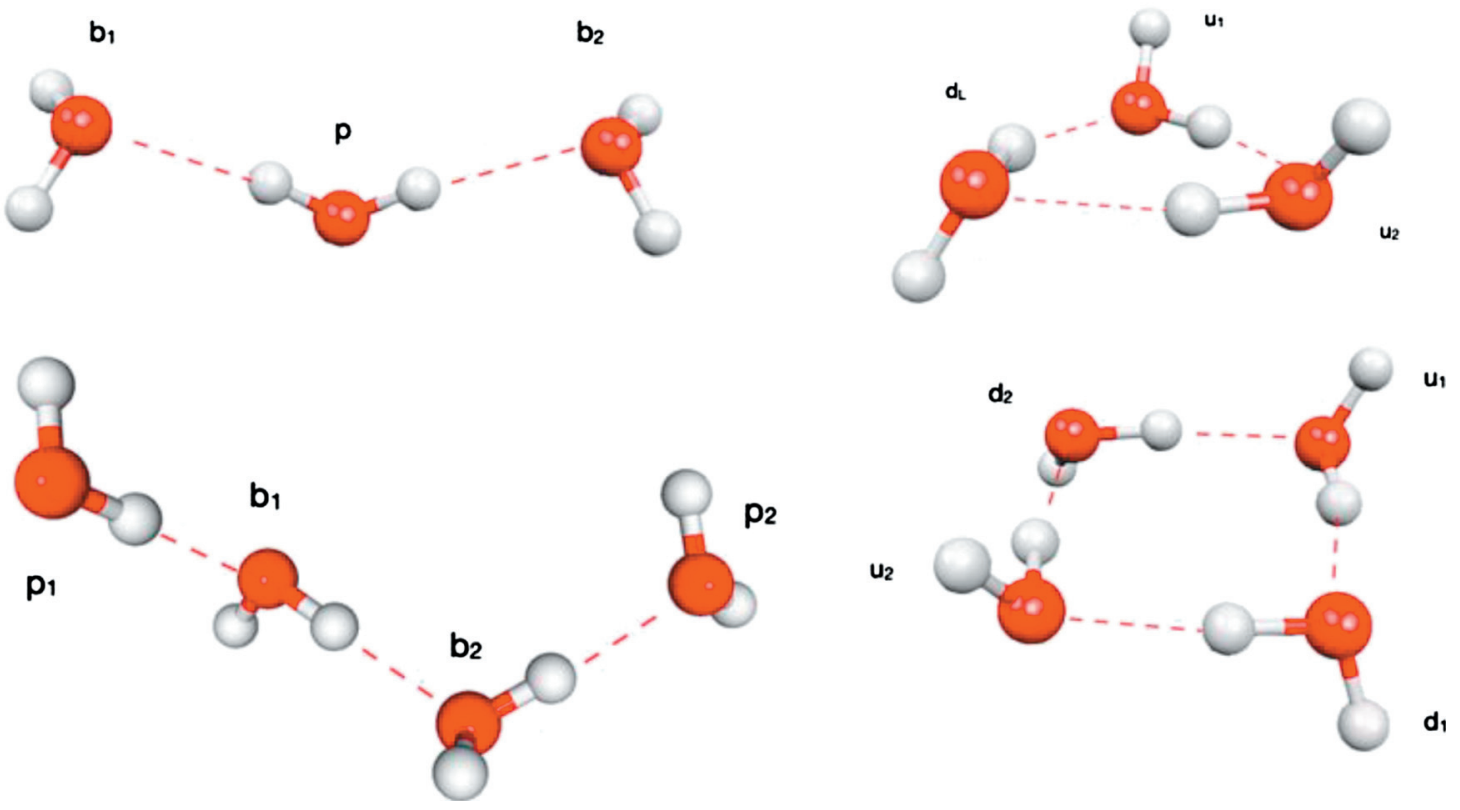

FIG. 1. Structures and labels (defined in the text) of the low-energy linear and cyclic conformers of $\left(\mathrm{H}_{2} \mathrm{O}\right)$.

\section{B. Vibrations}

Neutral $\mathrm{H}_{2} \mathrm{O}$ clusters are among the most challenging of small molecules to study. Nonetheless, their vibrational spectra are only partially known today. It is probably a close association between spectroscopy and theoretical calculations that can prompt such studies. ${ }^{88-90}$

\section{Harmonic data}

We would proceed to double check the applicability of the calculation conditions at B1LYP/(aug)-cc-pVTZ level based on the harmonic results (see Tables II and III and Figs. 2 and 3) for the determination of the vibration frequencies as

TABLE I. Water molecule and water clusters. B1LYP/cc-pVTZ binding energies corrected for ZPE and BSSE contributions, distances (angstroms), and angles (degrees). The values between brackets relate to the experimental data.

\begin{tabular}{|c|c|c|c|c|c|c|}
\hline & $\mathrm{H}_{2} \mathrm{O}$ & $\left(\mathrm{H}_{2} \mathrm{O}\right)_{2}$ & Cyclic $\left(\mathrm{H}_{2} \mathrm{O}\right)_{3}$ & Linear $\left(\mathrm{H}_{2} \mathrm{O}\right)_{3}$ & Cyclic $\left(\mathrm{H}_{2} \mathrm{O}\right)_{4}$ & Linear $\left(\mathrm{H}_{2} \mathrm{O}\right)$ \\
\hline $\mathrm{D}_{0}(\mathrm{kcal} / \mathrm{mol})$ & & $\begin{array}{c}-3.18 \\
{[-3.6 \pm 0.5]^{\mathrm{a}}} \\
-3.53^{\mathrm{b}}-3.09^{\mathrm{c}} \\
-5.18^{\mathrm{d}}-2.98^{\mathrm{e}}\end{array}$ & $\begin{array}{c}-13.21 \\
-12.71^{\mathrm{b}} \\
-10.88^{\mathrm{c}}-15.90^{\mathrm{d}}\end{array}$ & -5.10 & $\begin{array}{c}-24.58 \\
-24.18^{\mathrm{b}}-26.82^{\mathrm{d}}\end{array}$ & -9.63 \\
\hline $\mathrm{d}_{\mathrm{O}-\mathrm{O}}(\AA)$ & $\begin{array}{c}0.96^{\mathrm{f}} \\
{[0.9572]^{\mathrm{g}, \mathrm{h}}}\end{array}$ & $\begin{array}{c}2.92 \\
{[2.98]^{\mathrm{a}}} \\
2.90^{\mathrm{c}} 2.92^{\mathrm{j}}\end{array}$ & $\begin{array}{c}2.79(2) \\
{[2.94-2.97]^{\mathrm{a}}} \\
2.91^{\mathrm{b}} 2.79^{\mathrm{j}} 2.81^{\mathrm{j}}\end{array}$ & $\begin{array}{l}2.97(2) \\
2.90^{\mathrm{i}}\end{array}$ & $\begin{array}{c}2.74 \\
2.737-2.730^{b}\end{array}$ & $\begin{array}{c}2.795-2.887 \\
2.91^{\mathrm{i}}\end{array}$ \\
\hline$\delta_{(\mathrm{HOH})}(\mathrm{deg})$ & $\begin{array}{c}104.6 \\
{[104.52]^{\mathrm{g}, \mathrm{h}}}\end{array}$ & $\begin{array}{c}104.8-105.5 \\
105.0-105.4^{\mathrm{b}} \\
104.2^{\mathrm{e}}\end{array}$ & $\begin{array}{c}105.6-105.7 \\
105.8-106.2^{b}\end{array}$ & $105.4-106.2$ & & $104.9-106.0$ \\
\hline$\delta_{(\mathrm{HOH})}(\mathrm{deg})$ & & $\begin{array}{c}173.1 \\
{[174 \pm 20]^{\mathrm{k}}} \\
173.8^{\mathrm{b}} 171.7^{\mathrm{c}}\end{array}$ & $\begin{array}{c}151.0-152.7 \\
150.0-151.9^{\mathrm{b}} \\
148.6-151.3^{\mathrm{c}}\end{array}$ & 106.1 & $\begin{array}{c}162.7 \\
168.1-168.7^{b}\end{array}$ & 106.0 \\
\hline
\end{tabular}

${ }^{\mathrm{a}}$ Reference $81(\nu=0)$.

${ }^{\mathrm{b}}$ DFT-PP gradient corrected density functional: Ref. 82.

${ }^{\mathrm{g}}$ Reference 84

${ }^{\mathrm{c}} \mathrm{MP} 2$ /aug-cc-pVTZ, Ref. 83.

${ }^{\mathrm{d}} \Delta E$ (TTM3-F potential), Ref. 56.

${ }^{\mathrm{e}} \mathrm{CCSD}(\mathrm{T}) /$ aug-cc-pVTZ (avtz), Ref. 62.

${ }^{\mathrm{f}} \mathrm{d}_{\mathrm{O}-\mathrm{H}}$ value for the monomer.

${ }^{\mathrm{h}} \mathrm{d}_{\mathrm{O}-\mathrm{H}}(\AA)$.

${ }^{\mathrm{i}} \mathrm{MD}$, Refs. 75 and 83.

${ }^{\mathrm{j}} \mathrm{MP} 2 / 6-311++\mathrm{G}(3 \mathrm{~d}, 3 \mathrm{p})$, Ref. 85 .

${ }^{\mathrm{k}}$ Reference 86. 
TABLE II. Calculated harmonic frequencies of the cyclic trimer $\left(\mathrm{H}_{2} \mathrm{O}\right)_{3}$. The values between brackets relate to the difference between the CCSD(T)/avtz Bowman's reference values (Ref. 82) and other levels of theories.

\begin{tabular}{|c|c|c|c|c|c|c|c|}
\hline Mode & B1LYP/cc-pVTZ & B1LYP/aug-cc-pVTZ & B3LYP/cc-pVTZ & MP2/cc-pVTZ & $\operatorname{CCSD}(\mathrm{T}) / \mathrm{avtz}^{\mathrm{a}}$ & $\operatorname{PES}(1,2,3)^{\mathrm{b}}$ & $\mathrm{cc}-\mathrm{VSCF}^{\mathrm{c}}$ \\
\hline$\nu_{1}$ & $1661(+4)$ & $1645(-12)$ & $1653(-4)$ & $1667(+10)$ & 1657 & $1659(+2)$ & $1635(-22)$ \\
\hline$\nu_{2}$ & $1668(+8)$ & $1647(-13)$ & $1659(-1)$ & $1672(+12)$ & 1660 & $1663(+3)$ & $1639(-21)$ \\
\hline$\nu_{3}$ & $1683(+1)$ & $1670(-12)$ & $1675(-7)$ & $1692(+10)$ & 1682 & $1687(+5)$ & $1671(-11)$ \\
\hline$\nu_{4}$ & $3541(-66)$ & $3571(-36)$ & $3495(-112)$ & $3579(-28)$ & 3607 & $3629(+22)$ & $3658(+51)$ \\
\hline$\nu_{5}$ & $3615(-48)$ & $3628(-35)$ & $3575(-88)$ & $3659(-4)$ & 3663 & $3658(-5)$ & $3717(+54)$ \\
\hline$\nu_{6}$ & $3621(-50)$ & $3838(-33)$ & $3581(-90)$ & $3665(-6)$ & 3671 & $3667(-4)$ & $3726(+55)$ \\
\hline$\nu_{7}$ & $3883(+1)$ & $3883(+1)$ & $3862(-20)$ & $3922(+40)$ & 3882 & $3880(-2)$ & $3972(+90)$ \\
\hline$\nu_{8}$ & $3886(+1)$ & $3887(0)$ & $3865(-22)$ & $3926(+39)$ & 3887 & $3886(-1)$ & $3974(+87)$ \\
\hline$\nu_{9}$ & $3888(+1)$ & $3890(+3)$ & $3867(-20)$ & $3928(+41)$ & 3887 & $3888(+1)$ & $3976(+89)$ \\
\hline
\end{tabular}

${ }^{2}$ Reference 82 .

${ }^{\mathrm{b}}$ Reference 90

${ }^{\mathrm{c}}$ Reference 91.

well as intensities of both linear and cyclic water clusters. To this date, the only data we can refer concern the fundamental modes.

For the monomer water molecule, we have all the necessary experimental references, i.e., observed frequencies and the extrapolated harmonic frequency ${ }^{93}$ values. In addition, very precise calculations exist for this system. ${ }^{90,91,94} \mathrm{We}$ have used the calculation results by Bowman et al. at $\operatorname{CCSD}(T) / \operatorname{avxz}(x=t$ or $q)$ levels as references for both the monomer and the cyclic aggregates, which corresponds to the best possible theoretical levels and uses PES and dipole moment surface (DMS) force fields, adopted also in this work. However, to our knowledge, no calculated values are available for linear clusters as references.

In Fig. 2 we observe that the values obtained at B1LYP/ (aug)-cc-pVTZ, the method and level of theory we have postulated to best fit the studied systems, are indeed in very good agreement with experimental values and all on the same orders of magnitude as the reference values. The choice of both nonaugmented basis set and DFT approach remains, however, debatable. First, the inclusion of diffuse functions in the atomic basis set is mainly useful with the use of stronger correlated $a b$ initio methods. DFT methods are known to be less sensitive to the basis set completeness. Our calculations reported in Tables II and III and in Figs. 2 and 3 illus- trate these remarks. Second, the choice of DFT approach was mainly influenced by the ability to treat uniformly at the same level of theory the thousands of energy information necessary to determine both PES and DMS for the five systems studied in this work. Several other DFT methods have been tested, among which the very commonly adopted hybrid method of B3LYP. Note that the performance of the DFT functional CAM-B3LYP in the electronic structure part of the calculations has been also studied by comparison with results obtained using $\operatorname{CCSD}(\mathrm{T})$ calculations. No significant differences are noted between the results obtained with the two B3LYP approaches on the intermolecular vibrational modes description (to some extent for the $\nu_{a s, \mathrm{OH}}$ description). We can clearly see in Figs. 2 and 3 that the results obtained by using the B3LYP family methods differ strongly from all the best calculated values and appear to be strongly basis-set dependent. These approaches do not, in any case, allow to equal the data quality at B1LYP/(aug)-cc-pVXZ $(\mathrm{X}=\mathrm{T}$ or $\mathrm{Q})$ level. The same conclusion can be drawn for the MP2 approaches.

Figure 3 presents the results obtained for the water dimer cluster. The reference values considered for this system are those obtained by Bowman and co-workers at $\operatorname{CCSD}(\mathrm{T}) /$ avxz ( $\mathrm{x}=\mathrm{t}$ or $\mathrm{q})$ levels. ${ }^{63}$ From the analysis of these results we have drawn the same overall conclusions as for the

TABLE III. Calculated harmonic frequencies of the cyclic tetramer $\left(\mathrm{H}_{2} \mathrm{O}\right)_{4}$. The values between brackets relate to the difference between the CCSD(T)/avdz Bowman's reference values (Ref. 82) and other levels of theories.

\begin{tabular}{lccccc}
\hline \hline Mode & B1LYP/cc-pVTZ & B1LYP/aug-cc-pVTZ & MP2/cc-pVDZ & CCSD(T)/avd $^{\mathrm{a}}$ & ${\text { PES }(1,2,3)^{\mathrm{a}}}$ \\
\hline$\nu_{1}$ & $1668(+15)$ & $1649(-4)$ & $1637(-16)$ & 1653 & $1672(+19)$ \\
$\nu_{2}$ & $1677(+11)$ & $1663(-3)$ & $1653(-13)$ & 1666 & $1677(+11)$ \\
$\nu_{3}$ & $1677(+11)$ & $1663(-3)$ & $1653(-13)$ & 1666 & $1677(+11)$ \\
$\nu_{4}$ & $1702(+9)$ & $1691(-2)$ & $1683(-10)$ & 1693 & $1696(+3)$ \\
$\nu_{5}$ & $3363(+17)$ & $3387(+41)$ & $3391(-55)$ & 3446 & $3558(+12)$ \\
$\nu_{6}$ & $3468(-58)$ & $3478(-49)$ & $3484(-42)$ & 3526 & $3593(+68)$ \\
$\nu_{7}$ & $3468(-59)$ & $3478(-49)$ & $3484(-43)$ & 3527 & $3593(+66)$ \\
$\nu_{8}$ & $3510(-49)$ & $3515(-44)$ & $3522(-37)$ & 3559 & $3608(+49)$ \\
$\nu_{9}$ & $3882(+21)$ & $3882(+21)$ & $3886(+25)$ & 3861 & $3876(+15)$ \\
$\nu_{10}$ & $3883(+22)$ & $3882(+21)$ & $3887(+25)$ & 3861 & $3889(+28)$ \\
$\nu_{11}$ & $3883(+22)$ & $3882(+21)$ & $3887(+26)$ & 3861 & $3889(+28)$ \\
$\nu_{12}$ & $3884(+22)$ & $3883(+23)$ & $3887(+26)$ & 3861 & $3889(+28)$ \\
\hline \hline
\end{tabular}

${ }^{\mathrm{a} R e f e r e n c e} 90$. 


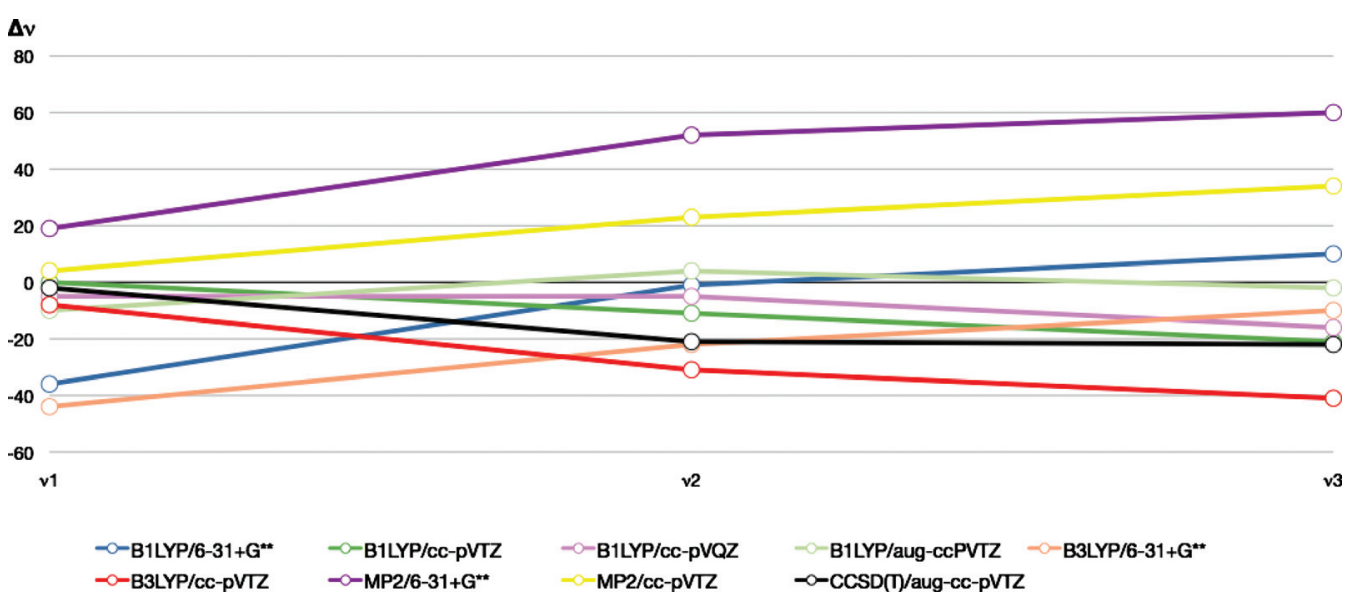

FIG. 2. Calculated harmonic frequencies of the water $\mathrm{H}_{2} \mathrm{O}$ monomer. The color lines relate to the difference between the experimental and the calculated harmonic frequencies (Ref. 92) at different levels of theory.

monomer, i.e., the calculation at B1LYP/cc-pVTZ levels best fits for the study of the vibrational system. Be aware that, however, there is a significant deviation in the stretching frequencies $\nu_{a s, \mathrm{OH}}$. As the hydrogen bonding exists between a donor and acceptor molecule in the dimer, the $\mathrm{OH}$ stretching frequency must be consequently altered. We can of course attribute this numerical gap to the use of a DFT approach for which the treatment of long range interactions is a priori less accurate than the strongly correlated $\operatorname{CCSD}(\mathrm{T})$ method. Nevertheless, this remains a hypothesis without any comprehensive experimental data for this system as well as any aggregate of larger size (see Tables II and III). To remedy this defect, we used the mixed CC//DFT type of approach: $:^{67}$ the harmonic part was all estimated at the most correlated level of theory in order to improve the description of intermolecular interaction and in order to include the quadratic terms in the force fields (and thus structural) calculated at the DFT levels.

Concerning the study of larger aggregates, there exists very few theoretical data references, other than those at CCSD(T)/avtz levels for the trimer. ${ }^{90}$ Recently, Bowman and co-workers developed a refined force field (denoted "HBB2") for the study of cyclic clusters with $\mathrm{n}=3,4$, and 6 . Moreover, they also developed a full-dimensional, $a b$ initio PES-like a sum of one-, two-, and three-body terms [noted
PES(1,2,3)] at the MP2/avtz level of theory in order to take into account all the strongest interactions between water systems. From the data presented in Tables II and III on the cyclic trimer and tetramer, we see again the applicability of the DFT approach for harmonic variational predictions in the floppy systems. The direct analysis of experimental data also shows that the accurate description of the bending modes and the asymmetric stretching modes is accessible by our approach. Subtle differences still remain regarding the description of the $\mathrm{OH}$ symmetric stretching modes (in particular, modes 4,5 , and 6 of the trimer) regardless of the theoretical method applied by the various authors to study the system. These discrepancies should not, however, prevent us from achieving the complete spectral analysis (the overtones, fundamentals, and harmonics bands) especially since uncertainties are also present in the assignment of the experimental spectra for the trimer. $^{63,82,95,96}$ In conclusion, harmonic B1LYP/(aug)-cc-pVTZ approach appears as the most suitable method for the present study.

\section{Anharmonic data}

In this approach the force fields are determined at (CC//)-B1LYP/cc-pVXZ level, and the vibrational Schrodinger equation is variationally solved by using the two

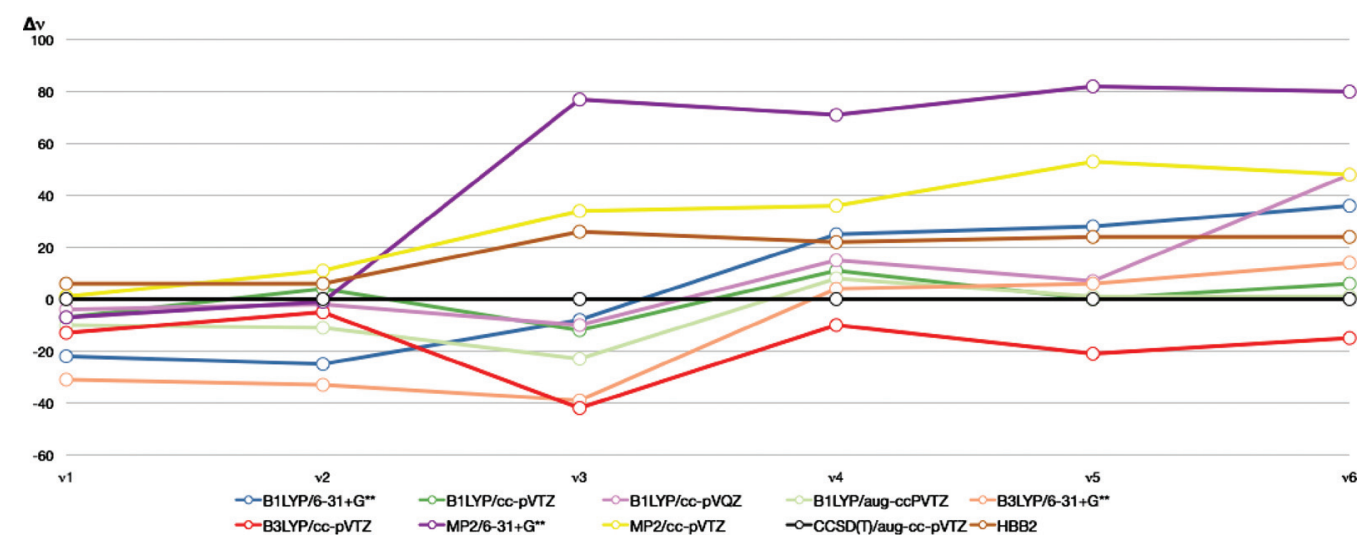

FIG. 3. (3n-6)-k calculated harmonic frequencies of the water $\left(\mathrm{H}_{2} \mathrm{O}\right)_{\mathrm{n}=2}$ dimer ( $\mathrm{k}$ torsional modes). The color lines relate to the difference between the $\operatorname{CCSD}(\mathrm{t}) / \mathrm{avtz}$ harmonic frequencies (Ref. 62) (black circle) and other levels of theories. 
electrical and mechanical anharmonic hypotheses for the study of all the intramolecular vibrational modes, i.e., even those associated with the anharmonic $\mathrm{OH}$ vibrators and their combined modes. This method should be a good compromise between the known approaches to this date such as those using the highest feasible level of ab initio electronic methods or using more or less sophisticated empirical or semiempirical many-body potentials. Intensities are finally calculated to both achieve the precise assignment of the spectra and to remove many ambiguities.

The results obtained in this work on combinations, overtones, and fundamental and listed in Tables IV-VI allow here several new insights as well as findings concerning the vibrational study of water cluster systems and in particular for the study of water under supercritical conditions (Table VI). Corrections due to mechanic anharmonicity are strong, as expected, because the aggregates are composed of light atoms. Modes are all strongly coupled. Moreover, without the information on the intensities, interpretations in this case are virtually impossible. Beyond the well-addressed electric anharmonic intensity values, their estimates regarding the NIR spectrum are indispensable.

Whatever the conditions under which these aggregates exist, supercritical or gaseous, all the fundamental vibrational bands associated with stretching and bending are active. However, among the overtones, only the spectral regions centered on the $\left(\nu_{2}+\nu_{3}\right)$ and $\left(\nu_{1}+\nu_{3}\right)$ monomer's combination modes are significantly active in the NIR (Table VI).

Despite the nature as well as the number of interactions between the monomers constituting the different aggregates, with each case being different, all the intramolecular vibration frequencies are greatly disturbed, the degree of which depends on whether the aggregate is cyclic or linear, and also on the size, even though this effect is much less pronounced than the form of the aggregate. The combination of these two effects makes the interpretation of the spectra less straightforward, mainly due to the widening and overlapping of the bands.

Finally, the key assignments resulted from this work are, in most cases, consistent with the experimental data mainly obtained for the gas phase. Nevertheless, some assignments still remain unclear or debatable, which implies the need to, first of all, clearly define the limits of the mathematical model used to solve the vibrational problem. Overall, the models used in this work are suitable for such a study although it should be pointed out that the model likely reaches its limits for these last systems, namely, the floppy systems, in terms of the size as well as the nature of the system.

The variational $\mathrm{P}_{-} \mathrm{VMWCI}_{2}$ results in Table $\mathrm{V}$ show that for certain modes there are unusual disagreements with those obtained by using a perturbational VPT2 approach (Table IV and Ref. 88). In general, when the quartic force field is the same in both approaches and when there is no overly strong resonances, the average difference found between the variational and the perturbational methods is around 5 or $10 \mathrm{~cm}^{-1}$ at most. But in our case, several stretching modes as well as angular bending modes seem to have abnormally disappeared. In addition, the largest differ- ences between experiment and theory were observed when variational treatment was applied. These findings led us to analyze the potential pitfalls of this approach in the study of floppy systems. To do this, we have mainly sought to enrich the description of successive vibrational subspaces by introducing up to 30000 configurations (in combinations of known eigenfunctions of the Hamiltonian of order zero) in the interaction configuration matrix for the study of each mode. The stability of the results associated with the resulting diagonalization shows a rapid convergence which we inevitably attribute to the fact that the spaces of the configurations used are a priori chosen correctly. Besides, these unusual differences have been systematically observed by all the other authors in previous studies on $\left(\mathrm{H}_{2} \mathrm{O}\right)_{n}(\mathrm{n}=1,2$, and 3 ) systems. Indeed, if one brings together the main results obtained by Gerber et al. ${ }^{91}$ Bowman et al., ${ }^{63}$ and Christiansen et al. ${ }^{105}$ where a disjoint variational algorithm is applied with the heterogeneous quality force fields, we notice (Table V) that all data differ among themselves as well as from the experimental assigned values even for the most intense modes. If the applicability of the variational method is not challenged in solving the vibrational Schrödinger equation, it is suggested that the analytical expression of the quartic force field is not sufficiently accurate for the global study of these flexible systems. In particular, the study of the free modes located at low wavenumbers requires, by all means, the development of appropriate adjustments. A calculation on the water monomer, using a $(11 \times 11 \times 11)$ grid method (DVR) and performed under the same conditions at the B1LYP/(aug)-cc-pVTZ levels, confirms the lack of accuracy of the potential function, since the frequencies are in excellent agreement with the experimental data well known for the monomer (Table V). In addition, we can see from the results reported by Bowman et al. that neither the quality of both the $a b$ initio $[\mathrm{CCSD}(\mathrm{T})]$ methods and the basis set (augcc-pVTZ) used to calculate all the points to be adjusted on the PES, nor the exploitation of the water at high frequencies near dissociation points (20 000 points have been calculated for simple dimer water molecules), would allow to correct the defects of the quartic model. In order to overcome these limitations we have decided to completely adjust the quartic function through decoupling all the free modes in the force fields. Indeed, as reported by Wang et al. ${ }^{63}$ the different energies of all minima affect the H-bond rearrangements and isomerization of the cluster and are not necessarily of importance to the "low resolution" monomer vibrations. So, the approach used in this work is based on a semirigid molecule method using only limited part of the potential. The good agreement between the calculated and the experimental frequencies indicates that the monomer vibrational modes are not strongly influenced by the torsional modes, which further supports the approach taken here. Unfortunately with the unavailability of any accurate experimental intensity information on water clusters, it is more difficult to judge the validity of the model. Nevertheless, tests made on the dimer system of water have not shown any significant influence of the torsional modes on both PES and DMS.

Data needed for both analysis and characterization of water clusters in the NIR under whatever circumstances are 
TABLE IV. VPT2 perturbational anharmonic frequencies $\left(\mathrm{cm}^{-1}\right)$, harmonic intensities $\left(\mathrm{I}_{\mathrm{h}}\right)$, and anharmonic intensities $\left(\mathrm{I}_{\mathrm{a}}\right)$ of the monomer, dimer, both cyclic and linear trimer, and cyclic and linear tetramer using the B1LYP/cc-pVTZ level of theory. These values are compared to the VPT2 reference values obtained by Dunn et al. (Ref. 88). Absolute intensities: HCAO local model CCSD(T)/aug-ccpVTZ.

\begin{tabular}{|c|c|c|c|c|c|c|}
\hline Mode & Description & $\begin{array}{c}\nu \\
\left(\mathrm{cm}^{-1}\right)\end{array}$ & $\begin{array}{l}\text { Theor. } \\
\qquad \mathrm{I}_{\mathrm{h}} \\
(\mathrm{K} \mathrm{m} / \mathrm{mol})\end{array}$ & $\begin{array}{c}\mathrm{I}_{\mathrm{a}} \\
(\mathrm{K} \mathrm{m} / \mathrm{mol})\end{array}$ & Expt. & $\begin{array}{c}\mathrm{I} \\
(\mathrm{K} \mathrm{m} / \mathrm{mol})\end{array}$ \\
\hline $\begin{array}{l}\sigma_{\mathrm{H}_{2}}{ }^{\left(\nu_{2}\right)}\left(\nu_{1}\right) \\
\nu_{s, \mathrm{OH}}\left(\nu_{3}\right) \\
\nu_{a s, \mathrm{OH}}\end{array}$ & & $\begin{array}{l}15961642^{\mathrm{a}} \\
36483660^{\mathrm{a}} \\
37343759^{\mathrm{a}}\end{array}$ & $\begin{array}{c}\mathrm{H}_{2} \mathrm{O} \\
71 \\
4 \\
42\end{array}$ & $\begin{aligned} 65 & 69^{\mathrm{a}} \\
3 & 2^{\mathrm{a}} \\
39 & 42^{\mathrm{a}}\end{aligned}$ & $\begin{array}{l}1595^{\mathrm{b}} \\
3651^{\mathrm{b}} \\
3756^{\mathrm{b}}\end{array}$ & $\begin{array}{c}54-72^{\mathrm{b}} \\
2-3^{\mathrm{b}} \\
42-45^{\mathrm{b}}\end{array}$ \\
\hline $\begin{array}{l}\sigma_{\mathrm{H}_{2\left(\mathrm{do}, \nu_{2}\right)}}\left(\mathrm{ac}, \nu_{1}\right) \\
\sigma_{\mathrm{H}_{2}\left(\mathrm{do}, \nu_{3}\right)} \\
\nu_{s, \mathrm{OH}}\left(\mathrm{ac}, \nu_{4}\right) \\
\nu_{s, \mathrm{OH}}\left(\mathrm{do}, \nu_{5}\right) \\
\nu_{a s, \mathrm{OH}}\left(\mathrm{ac}, \nu_{6}\right) \\
\nu_{a s, \mathrm{OH}}\end{array}$ & $\begin{array}{l}\sigma_{p_{2}}\left(l_{1}+l_{2}\right) \\
\sigma_{p_{1}}(l+L) \\
\nu_{p_{1}}(l+2 L) \\
\nu_{p_{2}}\left(l_{1}+l_{2}\right) \\
\nu_{p_{1}}(2 l-L) \\
\nu_{p_{2}}\left(l_{1}-l_{2}\right)\end{array}$ & $\begin{array}{llll}1598 & 1590^{\mathrm{c}} & 1642^{\mathrm{a}} \\
1619 & 1600^{\mathrm{c}} & 1662^{1} \\
3581 & 3597^{\mathrm{c}} & 3565^{\mathrm{a}} \\
3657 & 3671^{\mathrm{c}} & 3655^{\mathrm{a}} \\
3718 & 3769^{\mathrm{c}} & 3752^{\mathrm{a}} \\
3741 & 3776^{\mathrm{c}} & 3729^{\mathrm{a}}\end{array}$ & $\begin{array}{c}\left(\mathrm{H}_{2} \mathrm{O}\right)_{2} \\
84 \\
49 \\
280 \\
11 \\
66 \\
70\end{array}$ & $\begin{array}{c}7275^{\mathrm{a}} \\
4143^{\mathrm{a}} \\
290304^{\mathrm{a}} \\
810^{\mathrm{a}} \\
3969^{\mathrm{a}} \\
6280^{\mathrm{a}}\end{array}$ & $\begin{array}{c}1600^{\mathrm{d}} 1601^{\mathrm{e}} 1593^{\mathrm{f}} \\
1620^{\mathrm{d}} 1619^{\mathrm{e}} 1611^{\mathrm{f}} \\
3530^{\mathrm{g}} 13550^{\mathrm{e}} 3574^{\mathrm{f}} \\
3601^{\mathrm{j}} 3600^{\mathrm{g}} 3627^{\mathrm{e}} 3633^{\mathrm{f}} \\
3735^{\mathrm{j}} 3730^{\mathrm{g}} 3699^{\mathrm{e}} 3708^{\mathrm{f}} \\
3745^{\mathrm{h}} 3715^{\mathrm{k}}\end{array}$ & $\begin{array}{c}135^{\mathrm{h}} 133^{\mathrm{i}} \\
4^{\mathrm{i}} \\
32^{\mathrm{i}} \\
75^{\mathrm{i}}\end{array}$ \\
\hline 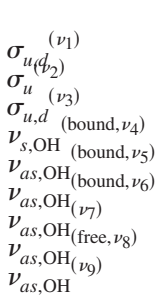 & $\begin{array}{c}\left(d-u_{2}\right) \\
u_{1}-\left(d+u_{2}\right) \\
d-u_{1}-u_{2} \\
d_{L}+u_{1, L}+u_{2, L} \\
2 d_{L}-2 u_{1, L}-u_{2, L} \\
d_{L}+2 u_{1, L}-2 u_{2, L} \\
2 u_{1, L}-d_{l}-u_{2, L} \\
\left(d_{l}-u_{2, l}\right)-\left(d_{L}-u_{2, L}\right)\end{array}$ & $\begin{array}{l}16181595^{1} \\
16451595^{1} \\
16321593^{1} \\
34093442^{1} \\
34653489^{1} \\
34713500^{1} \\
37073726^{1} \\
37083730^{1} \\
37093732^{1}\end{array}$ & $\begin{array}{c}\text { Cyclic }\left(\mathrm{H}_{2} \mathrm{O}\right)_{3} \\
46 \\
91 \\
32 \\
5 \\
556 \\
529 \\
81 \\
63 \\
48\end{array}$ & $\begin{array}{c}40 \\
80 \\
31 \\
4 \\
537 \\
507 \\
59 \\
46 \\
31\end{array}$ & $\begin{array}{c}1602^{\mathrm{m}} \\
1609^{\mathrm{d}} 1620^{\mathrm{m}} \\
1638^{\mathrm{d}} 1632^{\mathrm{m}} \\
3340^{\mathrm{n}} 3525^{\mathrm{m}} 3518^{\mathrm{o}} \\
3533^{\mathrm{j}} 3366^{\mathrm{n}} 3340^{\mathrm{n}} \\
3400^{\mathrm{p}} 3356^{\mathrm{p}} 3530^{\circ} \\
3726^{\mathrm{j}, \mathrm{o}} 3717^{\circ} \\
3703^{\mathrm{m}} 3707^{\mathrm{m}} 3695^{\mathrm{m}}\end{array}$ & \\
\hline 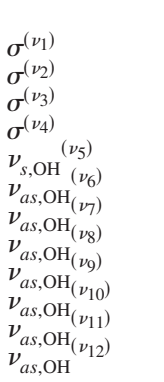 & $\begin{array}{c}u_{1}-u_{2}+d_{1}-d_{2} \\
u_{1}-u_{2}+2\left(d_{1}-d_{2}\right) \\
2\left(u_{1}-u_{2}\right)+\left(d_{1}-d_{2}\right) \\
u_{1}+u_{2}+d_{1}+d_{2} \\
u_{1, L}+u_{2, L}+d_{1, L}+d_{2, L} \\
d_{1, L}-d_{2, l} \\
u_{1, L}-u_{2, l} \\
u_{1, L}+u_{2, L}-d_{1, L}-d_{2, L} \\
u_{1, l}+u_{2, l}-d_{1, l}-d_{2, l} \\
d_{1, l}-d_{2, l} \\
u_{1, l}-u_{2, l} \\
u_{1, l}+u_{2, l}+d_{1, l}+d_{2, l}\end{array}$ & $\begin{array}{l}16541657^{\mathrm{r}} \\
16541657^{\mathrm{r}} \\
16541657^{\mathrm{r}} \\
16531672^{\mathrm{r}} \\
31793442^{\mathrm{r}} \\
33233496^{\mathrm{r}} \\
33233496^{\mathrm{r}} \\
33543521^{\mathrm{r}} \\
37033699^{\mathrm{r}} \\
37073700^{\mathrm{r}} \\
37073700^{\mathrm{r}} \\
37043701^{\mathrm{r}}\end{array}$ & $\begin{array}{c}\text { Cyclic }\left(\mathrm{H}_{2} \mathrm{O}\right)_{4} \\
101 \\
61 \\
61 \\
0 \\
0 \\
1384 \\
1384 \\
29 \\
87 \\
69 \\
69 \\
0\end{array}$ & $\begin{array}{c}87 \\
53 \\
53 \\
0 \\
0 \\
704 \\
704 \\
24 \\
74 \\
61 \\
61 \\
0\end{array}$ & $\begin{array}{l}3405,3416^{\circ} \\
3714,3717^{\circ}\end{array}$ & \\
\hline
\end{tabular}

\begin{tabular}{|c|c|c|c|c|}
\hline Mode & Description & $\nu\left(\mathrm{cm}^{-1}\right)$ & $\begin{array}{c}\text { Theor. } \\
\mathrm{I}_{\mathrm{h}}(\mathrm{K} \mathrm{m} / \mathrm{mol})\end{array}$ & $\mathrm{I}_{\mathrm{a}}(\mathrm{K} \mathrm{m} / \mathrm{mol})$ \\
\hline 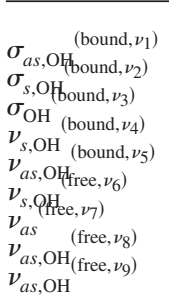 & 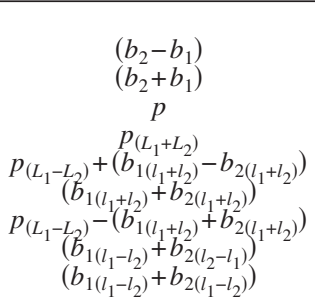 & $\begin{array}{c}\text { Linear }\left(\mathrm{H}_{2} \mathrm{O}\right)_{3} \\
1553 \\
1553 \\
1578 \\
3597 \\
3656 \\
3694 \\
3685 \\
3758 \\
3758\end{array}$ & $\begin{array}{c}97 \\
71 \\
28 \\
70 \\
532 \\
10 \\
32 \\
0 \\
159\end{array}$ & $\begin{array}{c}86 \\
63 \\
25 \\
67 \\
503 \\
8 \\
9 \\
0 \\
134\end{array}$ \\
\hline 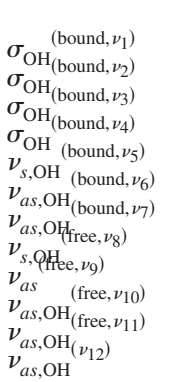 & $\begin{array}{c} \\
p \\
p \\
p \\
u_{1, L}+d_{2, l} \\
p_{\left(L_{1}-L_{2}\right)}-\left(b_{1\left(l_{1}+l_{2}\right)}+b_{2\left(l_{1}+l_{2}\right)}\right) \\
\left(b_{\left.1\left(l_{1}-l_{2}\right)+b_{2\left(l_{2}-l_{1}\right)}\right)}\right) \\
\left(b_{1\left(l_{1}-l_{2}\right)}+b_{2\left(l_{1}-l_{2}\right)}\right) \\
p_{\left(L_{1}-L_{2}\right)}\end{array}$ & $\begin{array}{c}\text { Linear }\left(\mathrm{H}_{2} \mathrm{O}\right)_{4} \\
1600 \\
1654 \\
1655 \\
1660 \\
3250 \\
3455 \\
3530 \\
3532 \\
3730 \\
3730 \\
3731 \\
3739\end{array}$ & $\begin{array}{c}83.0 \\
66.0 \\
58.5 \\
34.1 \\
895.3 \\
310.9 \\
346.6 \\
14.4 \\
82.5 \\
60.2 \\
48.2 \\
79.9\end{array}$ & $\begin{array}{c}69.1 \\
51.0 \\
44.8 \\
25.4 \\
745.0 \\
285.0 \\
319.1 \\
7.5 \\
53.0 \\
47.0 \\
37.1 \\
64.6\end{array}$ \\
\hline
\end{tabular}

${ }^{\mathrm{a}}$ Reference 48 .

${ }^{\mathrm{b}}$ Reference 15.

${ }^{c}$ Reference 91: VPT2 MP2(full)/aug-ccpVQZ.

${ }^{\mathrm{d}}$ Reference 92.

${ }^{\mathrm{e}}$ Reference 97: $\mathrm{N}_{2}$ matrix.

${ }^{\mathrm{f}}$ Reference 98: Ar matrix represents the experimental values.

${ }^{\mathrm{g}}$ Reference 83 .

${ }^{\mathrm{h}}$ Reference 13.

${ }^{\mathrm{i}}$ Reference 99: Ne matrix isolation experiment.
${ }^{\mathrm{j}}$ Reference 95.

${ }^{\mathrm{k}}$ Reference 100.

${ }^{1}$ Reference 91: VPT2 MP2(full)/aug-ccpVTZ.

${ }^{\mathrm{m}}$ Reference 101: Solid Ar.

${ }^{\mathrm{n}}$ Reference 102: Gas phase.

${ }^{\circ}$ Reference 88.

${ }^{\mathrm{p}}$ Reference 79 .

${ }^{\mathrm{q}}$ References 95, 103, and 104.

${ }^{\mathrm{r}}$ Reference 88: VPT2 scaled HF/6-31G*. 
TABLE V. Variational anharmonic frequencies $\left(\mathrm{cm}^{-1}\right)$ and anharmonic intensities (values between brackets- $\mathrm{Km} / \mathrm{mol}$ ) of monomer, dimer, both cyclic and linear trimer, and both cyclic and linear tetramer using the B1LYP/cc-pVTZ level of theory. These values are compared to the VCI and cc-VSCF reference values obtained. Values in bracket represent anharmonic intensities $(\mathrm{km} / \mathrm{mol})$.

\begin{tabular}{|c|c|c|c|c|c|c|}
\hline \multicolumn{7}{|c|}{$\mathrm{H}_{2} \mathrm{O}$} \\
\hline & Expt. & \multicolumn{2}{|c|}{ cc-VSCF } & $\begin{array}{c}\mathrm{VCI}^{\mathrm{a}, \mathrm{b}} \\
\operatorname{CCSD}(\mathrm{T}) / \mathrm{avtz}\end{array}$ & $\begin{array}{c}\text { P_VMWCI }_{2} \\
\text { B1LYP/cc-pVTZ }\end{array}$ & $\begin{array}{c}\operatorname{DVR}(11 \times 11 \times 11) \\
\text { B1LYP/cc-pVTZ }\end{array}$ \\
\hline$\nu_{2}$ & $1595(53.6-71.9)$ & 1543 & 1585 & $1576(71.6)$ & $1586(65.0)$ & 1582 \\
\hline$\nu_{1}$ & $3657(2.24-2.98)$ & 3696 & 3627 & $3696(1.90)$ & $3687(3.1)$ & 3654 \\
\hline$\nu_{3}$ & $3756(41.7-44.6)$ & 3768 & 3703 & 3779 (47.9) & $3780(39.0)$ & 3729 \\
\hline $2 \nu_{1}$ & $7202(0.32)$ & & 7174 & $7360(0.465)$ & $7345(0.51)$ & 7198 \\
\hline$\nu_{1}+\nu_{3}$ & $7250(4.85)$ & & 7159 & $7431(3.19)$ & $7426(3.75)$ & 7230 \\
\hline & & & & $\left(\mathrm{H}_{2} \mathrm{O}\right)_{2}$ & & \\
\hline
\end{tabular}

cc-VSCF

\begin{tabular}{|c|c|c|c|c|c|}
\hline & Expt. & $\mathrm{MP} 2 / \mathrm{VTZ}^{\mathrm{c}}$ & $\operatorname{CCSD}(\mathrm{T}) / \mathrm{avtz}^{\mathrm{d}}$ & $\mathrm{VCI}^{\mathrm{c}} \mathrm{CCSD}(\mathrm{T}) / \mathrm{avtz}$ & $\mathrm{P}_{-} \mathrm{VMWCI}_{2}$ B1LYP/cc-pVTZ \\
\hline$\nu_{1}$ & 1600 & 1564 & 1567 & 1590 & $1578(72.0)$ \\
\hline$\nu_{2}$ & 1620 & 1605 & 1603 & 1616 & $1602(41.1)$ \\
\hline$\nu_{3}$ & $3530-3601$ & 3565 & 3499 & 3590 & 3581 (290.3) \\
\hline$\nu_{4}$ & 3600 & 3647 & 3560 & 3625 & $3692(9.6)$ \\
\hline$\nu_{5}$ & $3730-3735$ & 3745 & 3665 & 3698 & $3752(39.1)$ \\
\hline$\nu_{6}$ & 3745 & 3724 & 3608 & 3718 & $3781(62.2)$ \\
\hline & & & & $\left(\mathrm{H}_{2} \mathrm{O}\right)_{3}$ & \\
\hline
\end{tabular}

Cyclic

Linear

Expt. $\quad$ cc-VSCF $^{c}$ MP2/TZP $\quad$ VCI $^{\mathrm{e}} \mathrm{CCSD}(\mathrm{T}) / \mathrm{avtz} \quad \mathrm{P}_{-} \mathrm{VMWCI}_{2}$ B1LYP/cc-pVTZ $\quad \mathrm{P}_{-} \mathrm{VMWCI}_{2}$ B1LYP/cc-pVTZ

\begin{tabular}{cccccc}
\hline$\nu_{1}$ & 1602 & 1592 & 1646 & $1586(40.1)$ & $1582(86)$ \\
$\nu_{2}$ & $1609-1620$ & 1595 & 1659 & $1594(79.8)$ & $1582(63)$ \\
$\nu_{3}$ & $1632-1638$ & 1623 & 1674 & $1610(30.8)$ & $1612(25)$ \\
$\nu_{4}$ & $3340-3525$ & 3283 & 3463 & $3353(4.0)$ & $3574(67)$ \\
$\nu_{5}$ & $3340-3533$ & 3457 & 3533 & $3443(537.2)$ & $3639(503)$ \\
$\nu_{6}$ & $3356-3400$ & 3429 & 3544 & $3453(507.1)$ & $3644(8)$ \\
$\nu_{7}$ & & 3738 & 3750 & $3746(59.1)$ & $3647(9)$ \\
$\nu_{8}$ & 3726 & 3723 & 3754 & $3749(45.9)$ & $3729(0)$ \\
$\nu_{9}$ & $3695-3703$ & 3725 & & & $3729(134)$ \\
& & & & & \\
\end{tabular}

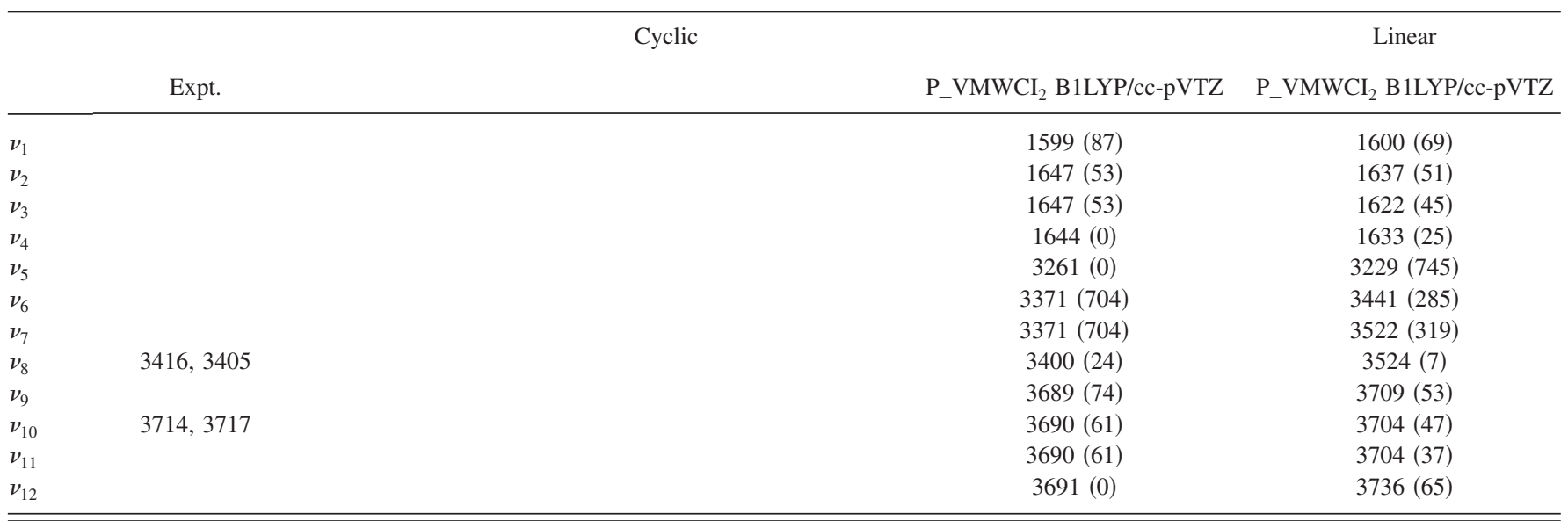

${ }^{\mathrm{a}}$ Christiansen et al., Ref. 105.

${ }^{\mathrm{b}}$ Gill et al., Ref. 106.

${ }^{\mathrm{c}}$ Gerber et al., Ref. 91.

finally reported in Table VI. These data are those needed to study mixtures in supercritical conditions where we suspected the existence of smaller assemblies (see our next developments reported in the paper, Ref. 108). Again, data are compared to experimental information's. Additional new
${ }^{\mathrm{d}}$ Kjaergaard et al., Ref. 48.

${ }^{\mathrm{e}}$ Bowman et al., Ref. 63.

data complete this study in the two 5000-5400 and $7100-7400 \mathrm{~cm}^{-1}$ spectral regions. Finally, variational and DVR anharmonic energies (Table V) and intensities (Table VI) are needed in order to accurately take into account all the numerous resonances. 
TABLE VI. Variational anharmonic overtone and combination frequencies $\left(\mathrm{cm}^{-1}\right)$ and intensities $(\mathrm{km} / \mathrm{mol})$ of monomer, dimer, and linear trimer systems using the B1LYP/cc-pVTZ level of theory. Mode descriptions refer to footnotes a-e and $\mathrm{g}-\mathrm{n}$.

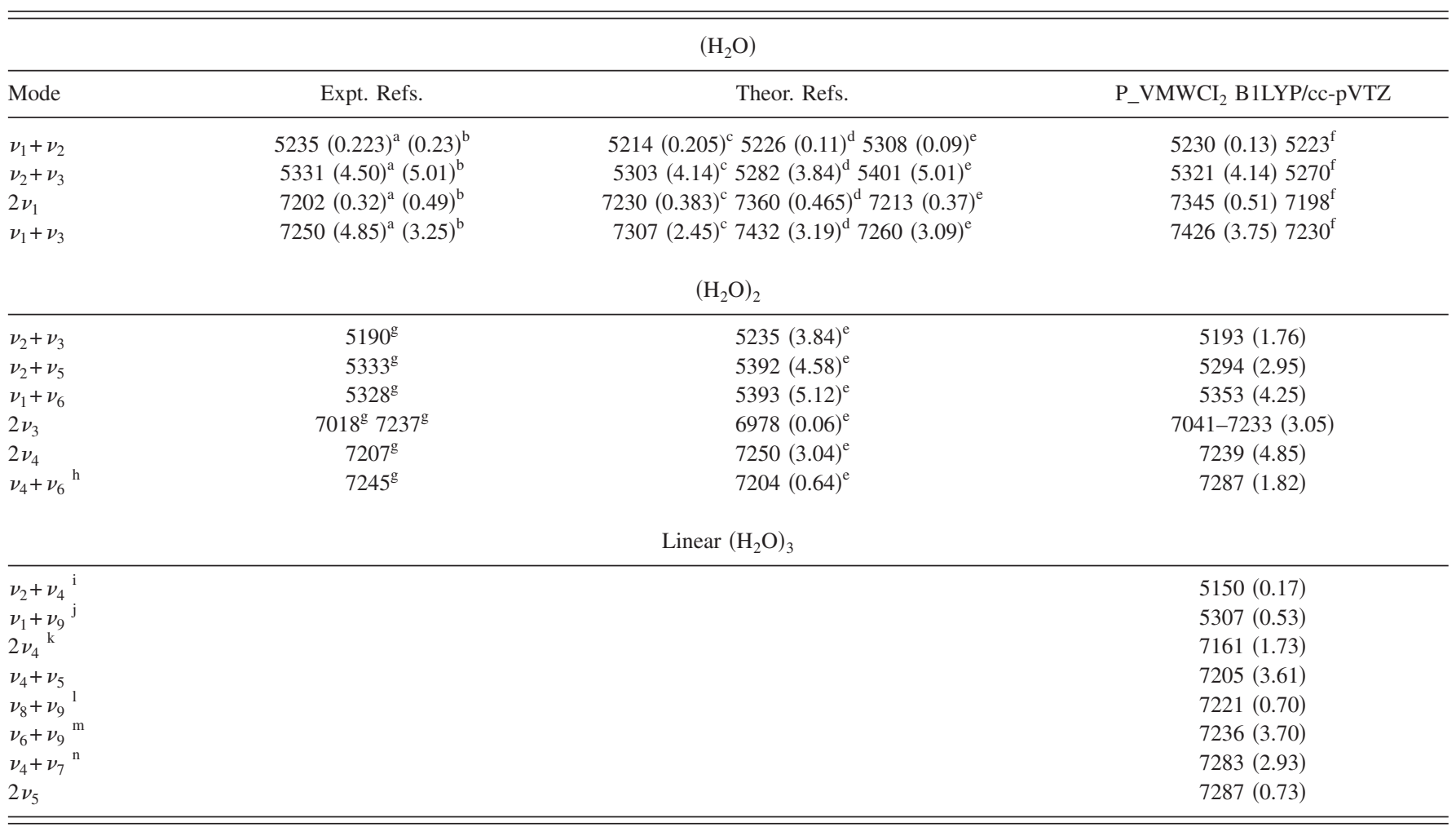

${ }^{\mathrm{a}}$ Experimental values: Ref. 107.

${ }^{\mathrm{b}}$ From the HITRAN 2006 database.

${ }^{c}$ Variational MULTIMODE: Ref. 15.

${ }^{\mathrm{d}}$ Variational VCI-CCSD(T)/avtz: Ref. 105.

${ }^{e}$ Reference 48: HCAO local model CCSD(T)/aug-ccpVTZ. Because of relative intensities, for each system the intensity values are scaled to the highest ones obtained in the present work (see Table IV for fundamental references).

${ }^{\mathrm{f}}$ DVR (B1LYP/cc-pVTZ) calculations.

${ }^{\mathrm{g}} \mathrm{Ne}$-matrix isolation experiments, Ref. 99.

${ }^{\mathrm{h}}$ Mixed at $16 \%$ with $2 \nu_{4}+\nu_{6}$.

${ }^{\mathrm{i}}$ Mixed at $9 \%$ with $\nu_{2}+\nu_{4}$.

${ }^{\mathrm{j}}$ Mixed at $36 \%$ with $\nu_{2}+\nu_{9}$

${ }^{\mathrm{k}}$ Mixed at $9 \%$ with $3 \nu_{4}$ and $16 \%$ with $\nu_{4}$.

${ }^{\mathrm{l}}$ Mixed at $16 \%$ with $\nu_{6}+\nu_{7}$ and $16 \%$ with $\nu_{5}+\nu_{6}$.

${ }^{\mathrm{m}}$ Mixed at $18 \%$ with $\nu_{7}+\nu_{8}$ and $10 \%$ with $\nu_{5}+\nu_{8}$.

${ }^{\mathrm{n}}$ Mixed at $12 \%$ with $\nu_{4}+\nu_{5}$.

\section{ACKNOWLEDGMENTS}

We acknowledge the Centre Informatique National de l'Enseignement Supérieur (CINES) for support of this work as well as the computational facilities provided by the computers of the M3PEC-Mesocenter, DRIMM-University Bordeaux 1, financed by the "Conseil Regional d'Aquitaine" and the French Ministry of Research and Technology. We express our sincere gratitude to Dr. Daisy Zhang, Dr. Roger Hiorns, Pr Max Chaillet, and to Dr. Ross Brown for helpful discussions and rereading.

${ }^{1}$ H. J. White, J. V. Sengers, D. B. Neumann, and J. C. Bellows, Physical Chemistry of Aqueous Systems: Meeting the Needs of Industry (Begell House, New York, 1995).

${ }^{2}$ R. W. Shaw, B. Brill, A. Clifford, A. Eckert, and E. U. Franck, Chem. Eng. News 69, 26 (1991)

${ }^{3}$ Y. Garrabos, B. L. Neindre, P. Subra, F. Cansell, and C. Pommier, Ann. Chim. (Paris) 17, 55 (1992).

${ }^{4}$ M.-C. Bellissent-Funel, T. Tassaing, H. Zhao, D. Beysens, B. Guillot, and Y. Guissani, J. Chem. Phys. 107, 2942 (1997).

${ }^{5}$ T. Tassaing and M.-C. Bellissent-Funel, J. Chem. Phys. 113, 3332 (2000).
${ }^{6}$ T. Tassaing, Y. Danten, and M. Besnard, J. Mol. Liq. 101, 149 (2002).

${ }^{7}$ M. Boero, K. Terakura, T. Ikeshoji, C. C. Liew, and M. Parrinello, J. Chem. Phys. 115, 2219 (2001).

${ }^{8}$ V. M. Leite dos Santos, F. G. B. Moreira, and R. L. Longo, Chem. Phys. Lett. 390, 157 (2004).

${ }^{9}$ J. Martí, J. Chem. Phys. 110, 6876 (1999).

${ }^{10}$ K. Alexander, S. Dirk, and V. J. Peter, Chem. Phys. 128, 244510 (2008).

${ }^{11}$ H. M. Lee, S. B. Suh, J. Y. Lee, P. Tarakeshwar, and K. S. Kim, J. Chem. Phys. 112, 9759 (2000).

${ }^{12}$ I. Baraille, C. Larrieu, A. Dargelos, and M. Chaillet, Chem. Phys. 273, 91 (2001)

${ }^{13}$ M. N. Slipchenko, K. E. Kuyanov, B. G. Sartakov, and A. F. Vilesov, J. Chem. Phys. 124, 241101 (2006).

${ }^{14}$ G. R. Low and H. G. Kjaergaard, J. Chem. Phys. 110, 9104 (1999).

${ }^{15}$ R. Burcl, S. Carter, and N. C. Handy, Chem. Phys. Lett. 380, 237 (2003) and references therein.

${ }^{16}$ D. Bégué, N. Gohaud, C. Pouchan, P. Cassam-Chenaï, and J. Lievin, J. Chem. Phys. 127, 164115 (2007).

${ }^{17}$ P. Cassam-Chenaï and J. Lievin, J. Comput. Chem. 27, 627 (2006).

${ }^{18}$ P. Seidler, E. Matito, and O. Christiansen, J. Chem. Phys. 131, 034115 (2009).

${ }^{19}$ J. M. Bowman, T. Carrington, and H.-D. Meyer, Mol. Phys. 106, 2145 (2008) and references therein.

${ }^{20}$ D. Bégué, I. Baraille, N. Gohaud, C. Darrigan, and C. Pouchan, 
P_ANHAR_V2.0, IPREM-ECP, UMR-CNRS 5254, Université de Pau et des Pays de 1'Adour, 2009.

${ }^{21}$ N. Gohaud, D. Bégué, C. Darrigan, and C. Pouchan, J. Comput. Chem. 26, 743 (2005).

${ }^{22}$ O. Vendrell, F. Gatti, and H.-D. Meyer, Angew. Chem., Int. Ed. 46, 6918 (2007).

${ }^{23}$ F. N. Keutsch, J. D. Cruzan, and R. J. Saykally, Chem. Rev. (Washington, D.C.) $\mathbf{1 0 3}, 2533$ (2003).

${ }^{24}$ E. B. Wilson, Jr., J. C. Decius, and P. C. Cross, Molecular Vibration (McGraw-Hill, New York, 1995).

${ }^{25}$ H. G. Kjaergaard, G. R. Low, T. W. Robinson, and D. L. Howard, J. Phys. Chem. A 106, 8955 (2002).

${ }^{26}$ J. Pliva, J. Mol. Spectrosc. 139, 278 (1990).

${ }^{27}$ A. Willetts and N. C. Handy, Chem. Phys. Lett. 235, 286 (1995)

${ }^{28}$ J. M. L. Martin, T. J. Lee, P. R. Taylor, and J.-P. François, J. Chem. Phys. 103, 2589 (1995)

${ }^{29}$ V. Barone, J. Chem. Phys. 122, 014108 (2005).

${ }^{30}$ E. L. Sibert, J. Chem. Phys. 88, 4378 (1988).

${ }^{31}$ C. Iung, F. Ribeiro, and E. L. Sibert, J. Phys. Chem. A 110, 5420 (2006)

${ }^{32}$ J. M. Bowman, J. Chem. Phys. 68, 608 (1978).

${ }^{33}$ G. D. Carney, L. L. Sprandel, and C. W. Kern, in Advances in Chemical Physics, edited by I. Prigogine and S. A. Rice (Wiley, New York, 1978), Vol. 37, pp. 305-379.

${ }^{34}$ M. B. Hansen, M. Sparta, P. Seidler, D. Toffoli, and O. Christiansen, J. Chem. Theory Comput. 6, 235 (2010).

${ }^{35}$ A. A. Adesokan, E. Fredj, E. C. Brown, and R. B. Gerber, Mol. Phys 103, 1505 (2005).

${ }^{36}$ N. J. Wright and R. B. Gerber, J. Chem. Phys. 114, 8763 (2001).

${ }^{37}$ P. Eggert, A. Viel, and C. Leforestier, Comput. Phys. Commun. 128, 315 (2000)

${ }^{38}$ J. M. Bowman, K. Christoffel, and F. Tobin, J. Phys. Chem. 83, 905 (1979).

${ }^{39}$ K. M. Christoffel and J. M. Bowman, Chem. Phys. Lett. 85, 220 (1982).

${ }^{40}$ J. Chang, N. Moiseyev, and R. E. Wyatt, J. Chem. Phys. 84, 4997 (1986).

${ }^{41}$ M. Neff and G. Rauhut, J. Chem. Phys. 131, 124129 (2009).

${ }^{42}$ C. Pouchan and K. Zaki, J. Chem. Phys. 107, 342 (1997).

${ }^{43}$ C. Pouchan, M. Aouni, and D. Bégué, Chem. Phys. Lett. 334, 352 (2001).

${ }^{44}$ I. Baraille, A. Dargelos, C. Larrieu, and M. Chaillet, Chem. Phys. 282, 9 (2002).

${ }^{45}$ Y. Scribano and D. M. Benoit, Chem. Phys. Lett. 458, 384 (2008).

${ }^{46}$ O. Christiansen, J. Chem. Phys. 120, 2149 (2004).

${ }^{47}$ P. Seidler and O. Christiansen, J. Chem. Phys. 131, 234109 (2009).

${ }^{48}$ H. G. Kjaergaard, A. L. Garden, G. M. Chaban, R. B. Gerber, D. A. Matthews, and J. F. Stanton, J. Phys. Chem. A 112, 4324 (2008).

${ }^{49}$ D. P. Schofield and H. G. Kjaergaard, Phys. Chem. Chem. Phys. 5, 3100 (2003).

${ }^{50}$ H. G. Kjaergaard and B. R. Henry, J. Chem. Phys. 96, 4841 (1992).

${ }^{51}$ T. Taketsugu and D. J. Wales, Mol. Phys. 100, 2793 (2002).

${ }^{52}$ C. Leforestier, F. Gatti, R. S. Fellers, and R. J. Saykally, J. Chem. Phys. 117, 8710 (2002).

${ }^{53}$ S. S. Xantheas, C. J. Burnham, and R. J. Harrison, J. Chem. Phys. 116, 1493 (2002)

${ }^{54}$ R. Bukowski, K. Szalewicz, G. C. Groenenboom, and A. van der Avoid, Science 315, 1249 (2007).

${ }^{55}$ Y. Scribano and C. Leforestier, J. Chem. Phys. 126, 234301 (2007).

${ }^{56}$ G. S. Fanourgakis and X. Xantheas, J. Chem. Phys. 128, 074506 (2008).

${ }^{57}$ R. Bukowski, K. Szalewicz, G. C. Groenenboom, and A. van der Avoird, J. Chem. Phys. 128, 094314 (2008).

${ }^{58}$ A. Shank, Y. Wang, A. Kaledin, B. J. Braams, and J. M. Bowman, J. Chem. Phys. 130, 144314 (2009).

${ }^{59}$ MOLPRO, a package of ab initio programs designed by H.-J. Werner and P. J. Knowles, Version 2009.1, R. Lindh, F. R. Manby, M. Schütz et al.

${ }^{60}$ M. J. Frisch, G. W. Trucks, H. B. Schlegel et al., GAUSSIAN 09, Revision A.1, Gaussian, Inc., Wallingford, CT, 2009

${ }^{61}$ G. I. Csonka, A. Ruzsinsyzky, and J. P. Perdew, J. Phys. Chem. B 109, $21471(2005)$

${ }^{62}$ X. Huang, B. J. Braams, J. M. Bowman, R. E. A. Kelly, J. Tennyson, G. C. Groenenboom, and A. van der Avoird, J. Chem. Phys. 128, 034312 (2008).

${ }^{63}$ Y. Wang, S. Carter, B. J. Braams, and J. M. Bowman, J. Chem. Phys. 128, 071101 (2008)
${ }^{64}$ D. Boese, W. Klopper, and M. L. Martin, Int. J. Quantum Chem. 104, 830 (2005).

${ }^{65}$ D. Bégué, P. Carbonniere, and C. Pouchan, J. Phys. Chem. A 109, 4611 (2005).

${ }^{66}$ A. Dargelos, FORCE, IPREM-ECP, UMR-CNRS 5254, Université de Pau et des Pays de l'Adour, revised version, 2009.

${ }^{67}$ N. Gohaud, D. Bégué, and C. Pouchan, Int. J. Quantum Chem. 104, 773 (2005) and references therein.

${ }^{68}$ W. J. Hehre, R. Ditchfield, and J. A. Pople, J. Chem. Phys. 56, 2257 (1972).

${ }^{69}$ T. H. Dunning, Jr., J. Chem. Phys. 90, 1007 (1989).

${ }^{70}$ J. R. Lane and H. G. Kjaergaard, J. Chem. Phys. 131, 034307 (2009).

${ }^{71}$ J. C. Light, I. P. Hamilton, and J. V. Lill, J. Chem. Phys. 82, 1400 (1985).

${ }^{72}$ D. T. Colbert and W. H. Miller, J. Chem. Phys. 96, 1982 (1992).

${ }^{73}$ J. C. Light and T. Carrington, Adv. Chem. Phys. 114, 263 (2000).

${ }^{74}$ A. G. Kalinichev and S. V. Churakov, Chem. Phys. Lett. 302, 411 (1999).

75 A. G. Kalinichev and S. V. Churakov, Fluid Phase Equilib. 183-184, 271 (2001).

${ }^{76}$ K. Liu, M. G. Brown, C. Carter, R. J. Saykally, J. K. Gregory, and D. C. Clary, Nature (London) 381, 501 (1996).

${ }^{77}$ J. M. Ugalde, I. Alkorta, and J. Elguero, Angew. Chem., Int. Ed. 39, 717 (2000).

${ }^{78}$ R. Ludwig, Angew. Chem., Int. Ed. 40, 1808 (2001).

${ }^{79}$ J. E. Fowler and H. F. Schaeffer III, J. Am. Chem. Soc. 117, 446 (1995).

${ }^{80}$ D. J. Wales, J. Am. Chem. Soc. 115, 11180 (1993).

${ }^{81}$ L. A. Curtiss, D. J. Frurip, and M. Blander, J. Chem. Phys. 71, 2703 (1979).

${ }^{82}$ D. A. Estrin, L. Paglieri, G. Corongiu, and E. Clementi, J. Phys. Chem. 100, 8701 (1996).

${ }^{83}$ A. G. Kalinichev, Yu. E. Gorbaty, and A. V. Okhulkov, J. Mol. Liq. 82, 57 (1999).

${ }^{84}$ W. S. Benedict, N. Gaillan, and E. K. Plyer, J. Phys. Chem. 24, 1139 (1956).

${ }^{85}$ A. F. A. Vilela, P. R. P. Barreto, R. Gargano, and C. R. M. Cunha, Chem. Phys. Lett. 427, 29 (2006) and references therein.

${ }^{86}$ K. Kuchitsu and Y. Morino, Bull. Chem. Soc. Jpn. 38, 805 (1965).

${ }^{87}$ P. D. Haynes, C.-K. Skylaris, A. A. Mostofi, and M. C. Payne, Chem. Phys. Lett. 422, 345 (2006).

${ }^{88}$ M. E. Dunn, T. M. Evans, K. N. Kirschner, and G. C. Shields, J. Phys. Chem. A 110, 303 (2006).

${ }^{89}$ A. G. Csaszar and I. M. Mills, Spectrochim. Acta, Part A 53, 1101 (1997).

${ }^{90}$ Y. Wang, B. C. Shepler, B. J. Braams, and J. M. Bowman, J. Chem. Phys. 131, 054511 (2009).

${ }^{91}$ G. M. Chaban, J. O. Jung, and R. B. Gerber, J. Phys. Chem. A 104, 2772 (2000).

${ }^{92}$ J. B. Paul, R. A. Provencal, C. Chapo, K. Roth, R. Casaes, and R. J. Saykally, J. Phys. Chem. A 103, 2972 (1999).

${ }^{93}$ G. Strey, J. Mol. Spectrosc. 24, 87 (1967).

${ }^{94}$ G. Rauhut, G. Knizia, and H.-J. Werner, J. Chem. Phys. 130, 054105 (2009).

${ }^{95}$ F. Huisken, M. Kaloudis, and A. Kulcke, J. Chem. Phys. 104, 17 (1996).

${ }^{96}$ J. B. Paul, C. P. Collier, R. J. Saykally, J. J. Scherer, and A. O'Keefe, J. Phys. Chem. A 101, 5211 (1997).

${ }^{97}$ J. P. Perchard, Chem. Phys. 266, 109 (2001).

${ }^{98}$ P. W. Atkins and R. S. Friedman, Molecular Quantum Mechanics, 3rd ed. (Oxford University Press, Oxford, 1997).

${ }^{99}$ Y. Bouteiller and J. P. Perchard, Chem. Phys. 305, 1 (2004).

${ }^{100}$ Z. S. Huang and R. E. Miller, J. Chem. Phys. 91, 6613 (1989).

${ }^{101}$ J. R. Reimers and R. O. Watts, Chem. Phys. 85, 83 (1984).

${ }^{102}$ S. Welfert, D. Herren, and S. Leutwyler, J. Chem. Phys. 86, 3554 (1985).

${ }^{103}$ K. Nauta and R. E. Miller, Science 287, 293 (2000).

${ }^{104}$ J. Ceponkus, G. Karlstrom, and B. Nelander, J. Phys. Chem. A 109, 7859 (2005).

${ }^{105}$ P. Seidler, J. Kongsted, and O. Christiansen, J. Phys. Chem. A 111, 11205 (2007)

${ }^{106}$ C. Yeh Lin, A. T. B. Gilbert, and P. M. W. Gill, Theor. Chem. Acc. 120, 23 (2008).

${ }^{107}$ W. H. Green, A. Willetts, D. Jayatilaka, and N. C. Handy, Chem. Phys. Lett. 169, 127 (1990) and references therein.

${ }^{108}$ T. Tassaing, P. A. Garrain, D. Bégué, and I. Baraille, J. Chem. Phys. 133, 034103 (2010). 